\title{
EFFECTS OF HYDROGEN ON THE FRACTURE TOUGHNESS OF CrMO AND CrMOV STEELS QUENCHED AND TEMPERED AT DIFFERENT TEMPERATURES
}

\author{
L.B. Peral *, A. Zafra ${ }^{1 *}$, J. Belzunce* and C. Rodríguez* \\ ${ }^{1}$ Corresponding author: A. Zafra (+34 985182023) alfredyzafra@ ghotmail.com \\ *University of Oviedo, campus universitario, 33203, Gijón, Spain
}

\begin{abstract}
Tempering temperatures ranging between 500 and $720^{\circ} \mathrm{C}$ were applied in order to analyse the relationship between steel microstructure and the deleterious effect of hydrogen on the fracture toughness of different CrMo and CrMoV steels. The influence of hydrogen on the fracture behaviour of the steel was investigated by means of fracture toughness tests using CT specimens thermally pre-charged with hydrogen gas.

First, the specimens were pre-charged with gaseous hydrogen in a pressurized reactor at $19.5 \mathrm{MPa}$ and $450^{\circ} \mathrm{C}$ for $21 \mathrm{~h}$ and elasto-plastic fracture toughness tests were performed under different displacement rates. The amount of hydrogen accumulated in the steel was subsequently determined in order to justify the fracture toughness results obtained with the different steel grades. Finally, scanning electron microscopy was employed to study both the resulting steel microstructures and the fracture micromechanisms that took place during the fracture tests.

According to the results, hydrogen solubility was seen to decrease with increasing tempering temperature, due to the fact that hydrogen microstructural trapping is lower in relaxed martensitic microstructures, the strong effect of the presence of vanadium carbides also being noted in this same respect. Hydrogen embrittlement was also found to be much greater in the grades tempered at the lowest temperatures (with higher yield strength). Moreover, a change in the fracture micromechanism, from ductile (microvoid coalescence, MVC), in the absence of hydrogen, to intermediate (plasticity-related hydrogen induced cracking, PRHIC) and brittle (intergranular fracture, IG), was appreciated with the increase in the embrittlement indexes.
\end{abstract}

KEYWORDS: Hydrogen embrittlement, fracture toughness, quenched and tempered steels, thermally pre-charged specimens, failure micromechanisms.

\section{INTRODUCTION}

Hydrogen is considered a future alternative energy source to fossil fuels. Commercial fuel cell vehicles and hydrogen refueling stations are currently in construction in many countries. In such hydrogen infrastructures, different metallic components such as hydrogen tanks, pipes and valves are directly exposed to a high-pressure hydrogen gas environment. Under typical in-service hydrogen pressures of up to $70 \mathrm{MPa}$, it is well known that hydrogen can easily enter and diffuse into metals, thereby deteriorating their mechanical properties such as tensile strength, ductility, fracture toughness and fatigue crack propagation rate [1,2].

In general, hydrogen systems have typically been designed using alloys with a high resistance to hydrogen embrittlement, such as austenitic stainless steels and aluminium alloys. However, these metals have a lower strength and are more expensive than conventional structural steels, such as low-alloy steels [3, 4]. The best solution to this problem, based on the criteria of economy and performance, would be to use medium- and high-strength tempered martensitic steels, which allow decreasing pipe and vessel thicknesses and hence a lower cost of the steel.

Cr-Mo and Cr-Mo-V steels are frequently used in the quenched and tempered condition when a good combination of strength and toughness is required. They also have high fatigue strength, thus far being an excellent choice in the manufacture of vessels and pipes able to work under high-pressure hydrogen gas [5, 6]. Nevertheless, it is well known that high strength steels are more sensitive to hydrogen embrittlement (HE) than low-strength grades, this susceptibility increasing with the strength level of the steel $[7,8]$. In order to overcome this drawback, they may be tempered at high temperatures, where their strength and hardness significantly decline, as was shown recently in [9], where the 
application of a tempering treatment of $650^{\circ}$ and $700^{\circ} \mathrm{C}$ during two hours gave rise to the best notched tensile behaviour when tested with internal hydrogen.

On the other hand, the susceptibility of structural materials to hydrogen-assisted fracture under high pressure hydrogen atmospheres can be assessed by (1) mechanical testing under high-pressure hydrogen gas (applying stress concurrent with hydrogen entrance), and (2) testing in air after pre-charging the specimens with hydrogen (applying stress following hydrogen exposure). These environmental conditions are referred to as external hydrogen and internal hydrogen, respectively [10]. In the case of external hydrogen, the measurement of mechanical properties under controlled hydrogen pressures requires the use of highly specialized facilities, as material test specimens may be exposed to high-pressure hydrogen gas while being subjected to specific mechanical loads.

Different authors $[5,11,12]$ have determined the fracture toughness of steels under external hydrogen conditions at high hydrogen pressures. They have demonstrated that the application of hydrogen pressure causes a significant decrease in the toughness of steels and that this property also depends strongly on the applied loading rate. According to San Marchi and Sommerday [11], fracture toughness of 2.25Cr1Mo steel in hydrogen gas is significantly lower than the fracture toughness in argon and these differences are sensitive to yield strength and hydrogen pressure, increasing as yield strength and hydrogen pressure increase. It was also recognized that Cr-Mo steels with yield strengths lower than $750 \mathrm{MPa}$ have demonstrated reliable performance in hydrogen services, with a lower bound fracture threshold in hydrogen gas of at least $50 \mathrm{MPam}^{1 / 2}$ [10]. On the other hand, using a low carbon non-alloyed steel (with a yield strength of 360MPa), Ogawa et al [13] reported significant fracture toughness degradation in $115 \mathrm{MPa}$ hydrogen gas pressure, but only a slight degradation in $0.7 \mathrm{MPa}$ hydrogen gas.

In contrast, the use of hydrogen pre-charged specimens is a readily available methodology and thermal pre-charging is a very convenient way to introduce controlled hydrogen contents into the samples. The thermal pre-charging method is relatively simple, as material test specimens are exposed to high-pressure hydrogen gas at a high temperature. In principle, the pressure and temperature are selected in accordance with the material and specimen dimensions so as to achieve a uniform hydrogen concentration in the specimen. In practice, uniform hydrogen concentrations can be achieved in conventional-sized specimens of structural steels within reasonable timeframes.

Pre-charging of specimens in hydrogen atmospheres may be limited to $450^{\circ} \mathrm{C}$ and 48 hours so as to completely avoid the methane reaction, which is the reaction between hydrogen atoms and solute carbon to produce a methane molecule [14]. With the aforementioned limitation, thermal pre-charging is able to produce samples with high hydrogen contents and uniform hydrogen distribution. However, hydrogen egress cannot be avoided during the cooling phase at the end of high temperature pre-charging until the extraction temperature is reached. Moreover, the final hydrogen concentration at room temperature is highly supersaturated, as hydrogen solubility depends exponentially on temperature [10].

Several studies on the effect of hydrogen on the fracture toughness of steels using thermally pre-charged specimens have also been performed. According to [14], the $\mathrm{J}$ crack growth initiation value, $\mathrm{J}_{0.2}$, respectively decreased from 600 to $60 \mathrm{~kJ} / \mathrm{m}^{2}$ and from 400 to $250 \mathrm{~kJ} / \mathrm{m}^{2}$ in CrMo and CrMoV steels, with this same parameter decreasing 5-fold between a loading rate of $0.3 \mathrm{~mm} / \mathrm{min}$ and that of $0.005 \mathrm{~mm} / \mathrm{min}$. Similarly, Liu et al. [15] observed a drop in the fracture toughness of a ferritic SA508-III steel thermally precharged at 10MPa, as the hydrogen content introduced in the steel increased (different $\mathrm{H}$ contents were achieved changing the reactor temperature between 150 and $300^{\circ} \mathrm{C}$ ). They also noticed a clear change in the fracture micromechanism from ductile microvoid coalescence (MVC) to a mixture fracture of dimples and cleavage facets.

Colombo et al. [16] reported a strong decrease in $\mathrm{J}_{\mathrm{Ic}}$ for the onset of crack growth in a quenched and tempered 4130 (CrMo) steel, from $215 \mathrm{~kJ} / \mathrm{m}^{2}$ in air to $22 \mathrm{~kJ} / \mathrm{m}^{2}$ in the presence of internal hydrogen (in this case the steel was electrochemically pre-charged). The authors stated that this fracture toughness embrittlement index was comparable with those obtained by Loginow and Phelps [17] in a similar steel grade tested in gaseous hydrogen at very high pressure. A significant deleterious effect of the presence of internal hydrogen on the fracture toughness of a high strength API X90 pipeline steel (with a $640 \mathrm{MPa}$ yield strength) was also reported by Li et al. [18] and such embrittlement was observed to increase with the thickness of the fracture specimen (higher constraint). Using also electrochemically hydrogen pre-charged specimens, Thomas et al. showed a very strong decrease of the plain-strain fracture toughness of an Aermet 100 steel (with a very high yield strength of $1765 \mathrm{MPa}$ ) from $143 \mathrm{MPam}^{-1 / 2}$ in air to 15 
$\mathrm{MPam}^{-1 / 2}$ with internal hydrogen, and fracture micromechanisms changed from ductile to transgranular cleavage [19]. Modifications of fracture micromechanisms form microvoid coalescence in air, to transgranular cleavage or even intergranular fracture with internal or external hydrogen, were also observed by many researchers $[13,14,15,20,21]$.

Anyway, there is now a need for wider-ranging research programs on this topic, and the use of thermally pre-charged specimens is very convenient for this purpose. Hydrogen pre-charged specimens were used in the present study to elucidate the effects of hydrogen on the fracture toughness of $42 \mathrm{CrMo} 4,2.25 \mathrm{Cr} 1 \mathrm{Mo}$ and $2.25 \mathrm{Cr} 1 \mathrm{MoV}$ steels, quenched and tempered at different temperatures, in order to obtain grades with different yield strengths. Furthermore, the effect of employing different displacement rates was also investigated.

\section{EXPERIMENTAL PROCEDURE}

\subsection{Materials and heat treatments}

Two CrMo and a CrMoV steels with the chemical compositions in weight $\%$ shown in Table 1 were used in this study.

Table 1. Chemical compositions of CrMo and CrMoV steels (wt. \%).

\begin{tabular}{|c|c|c|c|c|c|c|c|c|}
\hline Steel & $\mathrm{C}$ & $\mathrm{Mn}$ & $\mathrm{Si}$ & $\mathrm{P}$ & $\mathrm{S}$ & $\mathrm{Cr}$ & Mo & $\mathrm{V}$ \\
\hline 42CrMo4 & 0.42 & 0.62 & 0.18 & 0.008 & 0.002 & 0.98 & 0.22 & --- \\
\hline $2.25 \mathrm{Cr} 1 \mathrm{Mo}$ & 0.14 & 0.56 & 0.16 & 0.005 & 0.002 & 2.23 & 1 & --- \\
\hline $2.25 \mathrm{Cr} 1 \mathrm{MoV}$ & 0.15 & 0.52 & 0.09 & 0.006 & 0.002 & 2.27 & 1.1 & 0.31 \\
\hline
\end{tabular}

Hot rolled plates $\left(12 \mathrm{~mm}\right.$ thick) of $42 \mathrm{CrMo} 4$ were austenitized at $845^{\circ} \mathrm{C}$ for $40 \mathrm{~min}$, quenched in water, and then tempered at 5 different temperatures between 500 and $700^{\circ} \mathrm{C}$, for 2 hours. In addition, $2.25 \mathrm{Cr} 1 \mathrm{Mo}$ and $2.25 \mathrm{Cr} 1 \mathrm{MoV}$ steels were also respectively water quenched from 940 and $925^{\circ} \mathrm{C}$ and then tempered at the temperatures and times shown in Table 2. The reason for using different heat treatments was to obtain different steel grades so as to analyse the way hydrogen degrades the fracture toughness of one and the same steel but with different microstructures and strength levels.

Table 2. Heat treatments applied to CrMo and CrMoV steels.

\begin{tabular}{|c|c|}
\hline Steel grade & Heat treatments \\
\hline 42CrMo4_700 & $845^{\circ} \mathrm{C} / 40 \mathrm{~min}+$ water quenching $+700^{\circ} \mathrm{C} / 2 \mathrm{~h}$ tempering \\
\hline 42CrMo4_650 & $845^{\circ} \mathrm{C} / 40 \mathrm{~min}+$ water quenching $+650^{\circ} \mathrm{C} / 2 \mathrm{~h}$ tempering \\
\hline 42CrMo4_600 & $845^{\circ} \mathrm{C} / 40 \mathrm{~min}+$ water quenching $+600^{\circ} \mathrm{C} / 2 \mathrm{~h}$ tempering \\
\hline 42CrMo4_550 & $845^{\circ} \mathrm{C} / 40 \mathrm{~min}+$ water quenching $+550^{\circ} \mathrm{C} / 2 \mathrm{~h}$ tempering \\
\hline 42CrMo4_500 & $845^{\circ} \mathrm{C} / 40 \mathrm{~min}+$ water quenching $+500^{\circ} \mathrm{C} / 2 \mathrm{~h}$ tempering \\
\hline 2.25Cr1Mo_690 & $940^{\circ} \mathrm{C} / 30 \mathrm{~min}+$ water quenching $+690^{\circ} \mathrm{C} / 30 \mathrm{~h}$ tempering \\
\hline 2.25Cr1Mo_600 & $940^{\circ} \mathrm{C} / 30 \mathrm{~min}+$ water quenching $+600^{\circ} \mathrm{C} / 2 \mathrm{~h}$ tempering \\
\hline 2.25Cr1MoV_720 & $925^{\circ} \mathrm{C} / 30 \mathrm{~min}+$ water quenching $+720^{\circ} \mathrm{C} / 3 \mathrm{~h}$ tempering \\
\hline 2.25Cr1MoV_650 & $925^{\circ} \mathrm{C} / 30 \mathrm{~min}+$ water quenching $+650^{\circ} \mathrm{C} / 2 \mathrm{~h}$ tempering \\
\hline
\end{tabular}

\subsection{Hydrogen charging}

All the specimens were pre-charged with gaseous hydrogen in a high-pressure reactor and were kept in contact with gaseous hydrogen under a pressure of $19.5 \mathrm{MPa}$ at $450^{\circ} \mathrm{C}$ for $21 \mathrm{~h}$. After this holding time, the reactor was allowed to cool for $1 \mathrm{~h}$ until reaching a temperature of $85^{\circ} \mathrm{C}$. During this phase, the hydrogen pressure was maintained constant at 19.5 MPa to reduce hydrogen egress. All the pre-charged specimens were subsequently removed from the reactor and immersed in liquid nitrogen $\left(-196^{\circ} \mathrm{C}\right)$, where they were kept until the start of the corresponding test, once again in order to limit hydrogen losses.

\subsection{Measurement of hydrogen content}


The hydrogen content in the specimens was measured by means of thermal desorption analysis (TDA) using a Leco DH603 hydrogen analyser. The equipment's measurement principle is based on the difference in thermal conductivity between a reference gas flow of pure nitrogen and a secondary flow composed of nitrogen and the hydrogen thermally extracted from the sample kept at $1100^{\circ} \mathrm{C}$ for $400 \mathrm{~s}$. Cylindrical steel pins of $10 \mathrm{~mm}$ in diameter and $30 \mathrm{~mm} \mathrm{long}(\approx 20 \mathrm{~g})$ were used for this purpose. After extraction from the liquid nitrogen and before the measurement, each pin was cleaned in an ultrasonic bath with acetone for 5 minutes and carefully dried using cold air. Hydrogen content measurements were performed just after pre-charging, so as to determine the total hydrogen introduced into the steels, and after 5 days at room temperature to determine the strongly trapped hydrogen.

\subsection{Fracture toughness tests}

Fracture toughness characterization was performed using compact test $(\mathrm{CT})$ specimens with a width $\mathrm{W}=48 \mathrm{~mm}$, a thickness $B=12 \mathrm{~mm}$, and an initial notch $a_{n}=20 \mathrm{~mm}$. First, the specimens were fatigue pre-cracked at $\mathrm{R}=0.1 \mathrm{and} \mathrm{f}=10 \mathrm{~Hz}$, until obtaining a crack length versus width ratio, a/W=0.5, following the ASTM E1820 standard [22]. Lateral notches were then machined on both sides of the specimen until reaching a net thickness, $B_{n}=10 \mathrm{~mm}$, so as to ensure a plane strain state.

Fracture toughness tests without hydrogen were carried out under a nominal displacement rate of $1 \mathrm{~mm} / \mathrm{min}$. Hydrogen pre-charged specimens were tested under displacement rates of $1,0.1,0.01$ and $0.001 \mathrm{~mm} / \mathrm{min}$ (also depending on the steel grade) in order to study the influence of this parameter on HE.

Crack growth in the course of the tests was determined by means of the compliance method, carrying out $25 \%$ partial discharges using a CTOD gauge. The initial and final crack lengths were corrected by measuring them on the fracture surface of the broken specimen. The $\mathrm{J}$ value obtained in each discharge was calculated as the sum of its elastic and plastic components. The former was calculated from the stress intensity factor, $\mathrm{K}$, while the latter was obtained by integrating the area below the load-displacement plot.

The fracture toughness initiation parameter $J_{0.2 / B L}\left(\mathrm{~kJ} / \mathrm{m}^{2}\right)$ was used. This parameter corresponds to the value of $\mathbf{J}$ after a crack growth of $0.2 \mathrm{~mm}$ offset to the blunting line. Furthermore, in order to assess the effects of hydrogen in the crack propagation stage, the $\mathrm{J}_{1.2 / \mathrm{BL}}$ parameter ( $\mathrm{J}$ value corresponding to a crack propagation of $1.2 \mathrm{~mm}$ ) was also considered.

It should be noted that due to the high brittleness of the $42 \mathrm{CrMo} 4$ steel grades tempered at 550 and $500^{\circ} \mathrm{C}$, it was not possible to determine the value of $\mathrm{J}_{0.2 / \mathrm{BL}}$ when these steels were tested with internal hydrogen under low displacement rates. Therefore, the value of $\mathrm{P}_{\mathrm{Q}}$ for these steel grades was calculated from the Load-CTOD curve, $\mathrm{P}_{\mathrm{Q}}$ being the load obtained on the plot when decreasing the slope of the linear elastic line $5 \%$. This value was then used to estimate the $\mathrm{K}_{\mathrm{Q}}$ and $\mathrm{J}_{\mathrm{Q}}$ parameters following the specifications of the standard [22].

Finally, the decrease in fracture toughness caused by the presence of internal hydrogen was defined by means of the embrittlement index (EI), defined in Eq. (1) (EI varies from 0, no embrittlement at all, to 100\%, maximum possible hydrogen embrittlement).

$$
E I[\%]=\frac{X-X_{H}}{X} \cdot 100
$$

where $\mathrm{X}$ and $\mathrm{X}_{\mathrm{H}}$ are respectively the measured toughness property evaluated without and with internal hydrogen.

\subsection{Observation of microstructures and fracture surfaces}

The microstructures obtained after the application of the different heat treatments were observed by means of a scanning electron microscope (SEM JEOL-JSM5600) under an acceleration voltage of $20 \mathrm{kV}$. The samples were ground, polished with diamond paste and finally etched with Nital-2\%.

The fracture surfaces of the tested specimens were also analysed using the same scanning electron microscope under different magnifications.

\section{RESULTS}




\subsection{Steel microstructures}

The SEM microstructures of some of the 42CrMo steel grades are shown in Fig. 1, along with the microstructures of the $2.25 \mathrm{Cr} 1 \mathrm{Mo}$ and $2.25 \mathrm{Cr} 1 \mathrm{MoV}$ steels obtained after applying the aforementioned thermal treatments.

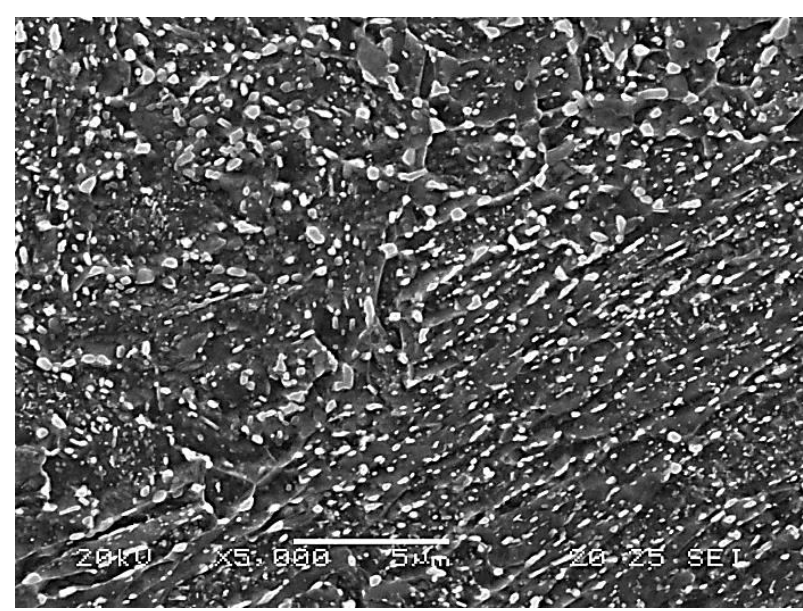

(a)

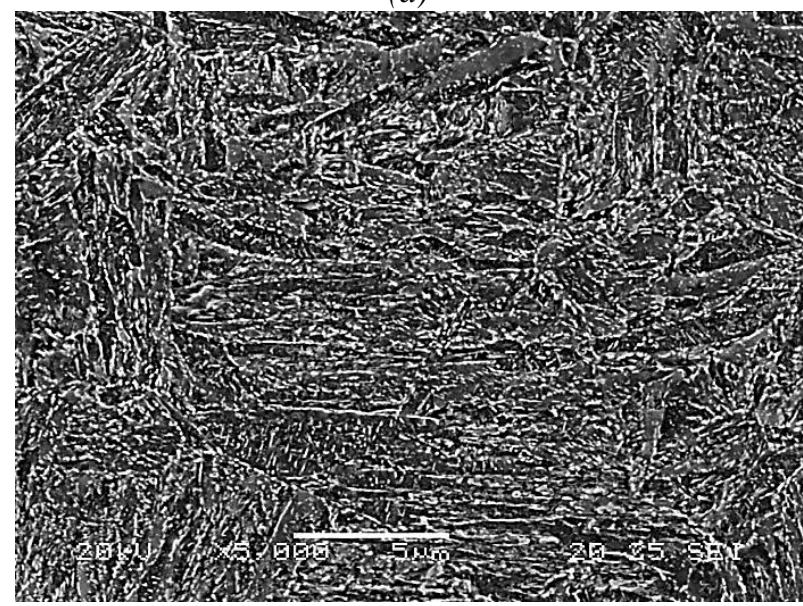

(c)

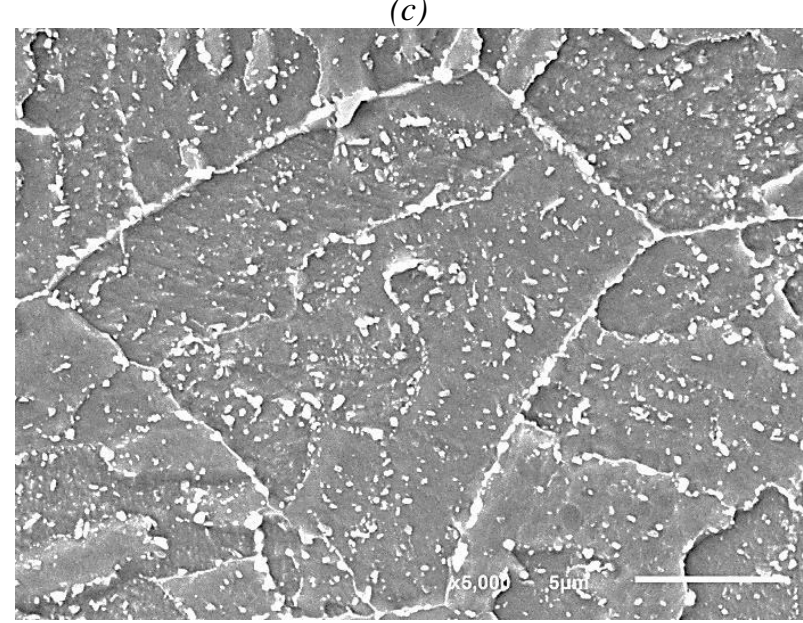

(e)

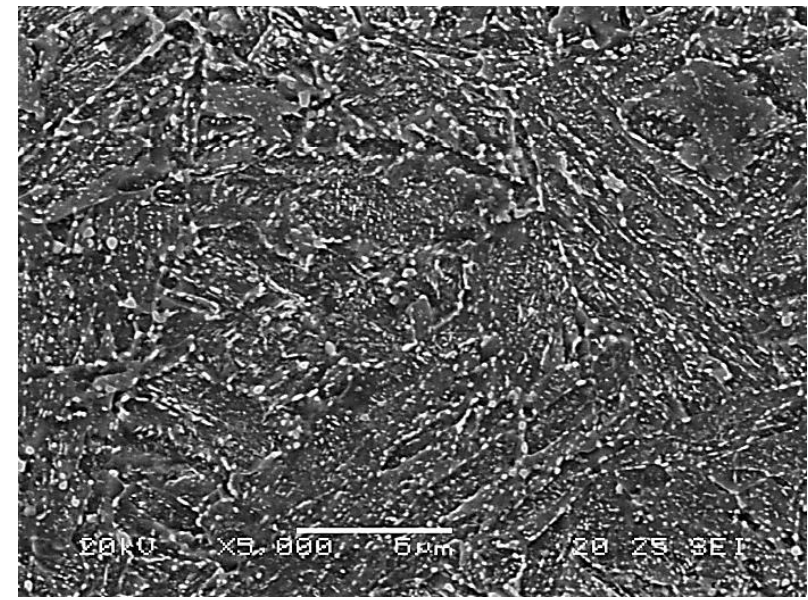

(b)

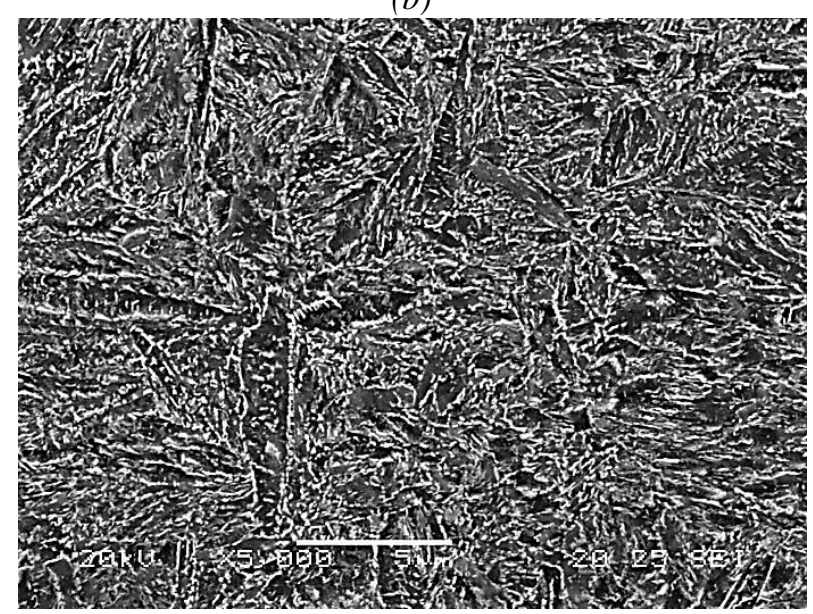

(d)

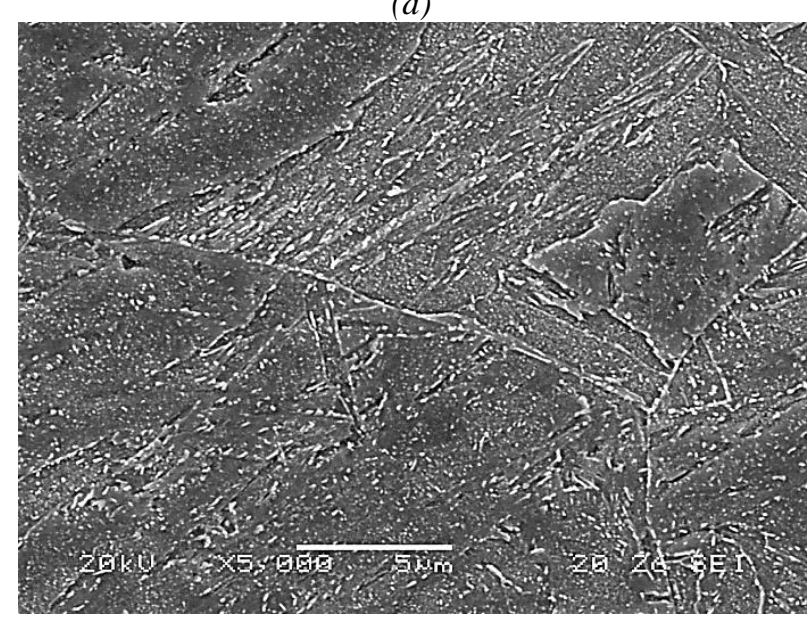

(f) 


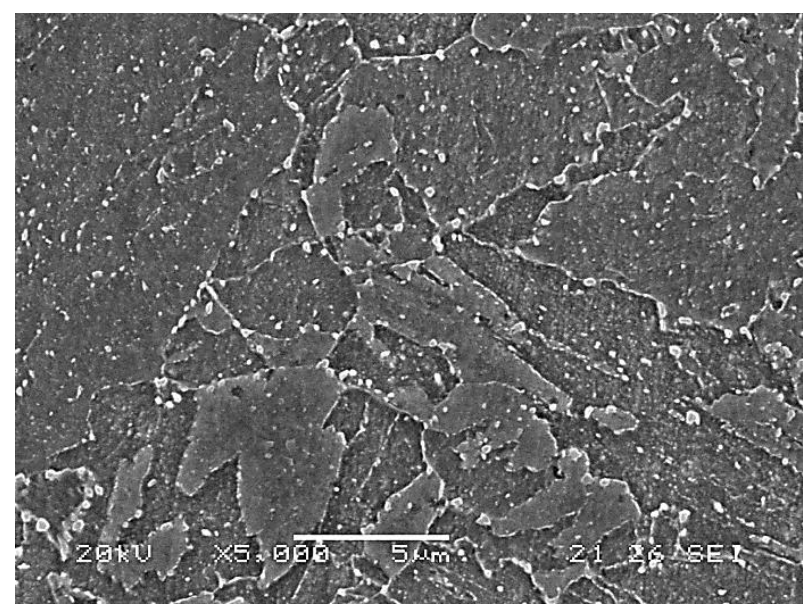

$(g)$

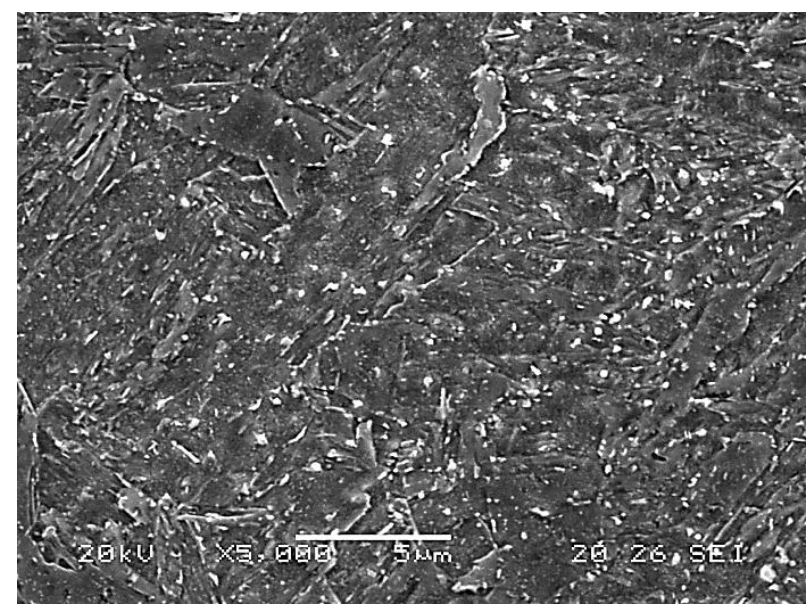

(h)

Figure 1. SEM microstructures of (a) 42CrMo4_700, (b) 42CrMo4_650, (c) 42CrMo4_600, (d) 42CrMo4_500, (e) 2.25Cr1Mo_690, (f) 2.25Cr1Mo_600, (g) 2.25Cr1MoV_720 and (h) 2.25Cr1MoV_650.

The obtained microstructure was in all cases tempered martensite, in which the profuse carbide precipitation that takes place during the tempering process can be clearly seen. Martensite internal residual stresses relax, dislocation rearrangement/annihilation and substructure recovery takes place, elongated carbides first precipitated in martensite block and packet boundaries break up, globulize and finally grow to yield a more uniform distribution with increasing tempering temperature [23]. Just as an example, compare the microstructures of 42CrMo4 steel quenched and tempered at $500^{\circ} \mathrm{C}$ (Fig. 1(d)) and $700^{\circ} \mathrm{C}$ (Fig. 1(a)). After tempering at $700^{\circ} \mathrm{C}$, carbides have larger size, a more spherical morphology and are distributed in a more uniform way.

The aforementioned microstructural differences give rise to the hardness and tensile properties listed in Table 3 . As expected, yield strength, $\sigma_{\mathrm{ys}}$, ultimate tensile strength, $\sigma_{\mathrm{uts}}$ and Brinell hardness, HB, progressively decrease with increasing tempering temperature, while the opposite occurs with tensile elongation, e, and reduction in area, RA.

Table 3. Tensile properties and Brinell hardness $(H B)$ of the different CrMo and CrMoV grades.

\begin{tabular}{|c|c|c|c|c|c|c|}
\hline Steel Grades & Heat treatment & $\sigma_{\text {ys }}[\mathrm{MPa}]$ & $\sigma_{\text {uts }}[\mathrm{MPa}]$ & $\mathrm{e}[\%]$ & $\mathrm{RA}[\%]$ & $\mathrm{HB}$ \\
\hline 42CrMo4_700 & $845^{\circ} \mathrm{C}+\mathrm{WQ}+\mathrm{T} 700^{\circ} \mathrm{C} / 2 \mathrm{~h}$ & 622 & 710 & 22 & 61 & 201 \\
\hline 42CrMo4_650 & $845^{\circ} \mathrm{C}+\mathrm{WQ}+\mathrm{T} 650^{\circ} \mathrm{C} / 2 \mathrm{~h}$ & 820 & 905 & 16 & 57 & 246 \\
\hline 42CrMo4_600 & $845^{\circ} \mathrm{C}+\mathrm{WQ}+\mathrm{T} 600^{\circ} \mathrm{C} / 2 \mathrm{~h}$ & 880 & 985 & 15 & 55 & 281 \\
\hline 42CrMo4_550 & $845^{\circ} \mathrm{C}+\mathrm{WQ}+\mathrm{T} 550^{\circ} \mathrm{C} / 2 \mathrm{~h}$ & 1023 & 1113 & 14 & 49 & 307 \\
\hline 42CrMo4_500 & $845^{\circ} \mathrm{C}+\mathrm{WQ}+\mathrm{T} 500^{\circ} \mathrm{C} / 2 \mathrm{~h}$ & 1086 & 1198 & 13 & 51 & 335 \\
\hline 2.25Cr1Mo_690 & $940^{\circ} \mathrm{C}+\mathrm{WQ}+\mathrm{T} 690^{\circ} \mathrm{C} / 30 \mathrm{~h}$ & 430 & 580 & 27 & 72 & 170 \\
\hline 2.25Cr1Mo_600 & $940^{\circ} \mathrm{C}+\mathrm{WQ}+\mathrm{T} 600^{\circ} \mathrm{C} / 2 \mathrm{~h}$ & 761 & 887 & 19 & 75 & 285 \\
\hline 2.25Cr1MoV_720 & $925^{\circ} \mathrm{C}+\mathrm{WQ}+\mathrm{T} 720^{\circ} \mathrm{C} / 3 \mathrm{~h}$ & 567 & 714 & 20 & 80 & 200 \\
\hline 2.25Cr1MoV_650 & $925^{\circ} \mathrm{C}+\mathrm{WQ}+\mathrm{T} 650^{\circ} \mathrm{C} / 2 \mathrm{~h}$ & 667 & 829 & 20 & 75 & 262 \\
\hline
\end{tabular}

Note also that steel grades with yield strengths between 430 and $1086 \mathrm{MPa}$ were produced. It is well known that hydrogen embrittlement increases with the strength level of the steel [5-9]; hence grades tempered at lower temperatures are expected to be more susceptible to HE.

\subsection{Hydrogen uptake}

All the hydrogen values measured in the different CrMo and CrMoV steel grades are shown in Table 4. The initial hydrogen content after thermal pre-charging, $\mathrm{C}_{\mathrm{H} 0}$, and the final hydrogen content, $\mathrm{C}_{\mathrm{Hf}}$, i.e. hydrogen strongly trapped and retained in the steel microstructure after a long time at room temperature (around five days in our tests) were determined. The difference between these two values is the diffusible hydrogen, i.e. weakly and reversibly trapped hydrogen able to move through the steel microstructure. An initial hydrogen content of between 0.6 and $1.9 \mathrm{ppm}$ was 
introduced in the different CrMo steel grades. Moreover, the final hydrogen content is even more dependent on the microstructure of the steel than the former value, decreasing as the tempering temperature increases, mainly due to stress relaxation and the reduction in dislocation density and internal interphases (martensite blocks and packets). On the other hand, CrMoV steel grades were able to absorb much larger hydrogen values due to the presence of very fine vanadium carbides $[14,24,25]$ that were strongly trapped in their microstructures. In this case, tempering at a higher temperature slightly increases the hydrogen trapping capacity of the steel, mainly due to differences in vanadium carbide precipitation, size and distribution.

Table 4. Initial $\left(\mathrm{C}_{\mathrm{HO}}\right)$, final $\left(\mathrm{C}_{\mathrm{Hf}}\right)$ and diffusible hydrogen $\left(\mathrm{C}_{\mathrm{HO}}-\mathrm{CH}_{\mathrm{H}}\right)$ measured in the different CrMo and CrMoV steel grades.

\begin{tabular}{|c|c|c|c|c|}
\hline Steel Grades & $\mathrm{HB}$ & $\mathrm{C}_{\mathrm{H} 0}[\mathrm{ppm}]$ & $\mathrm{C}_{\mathrm{Hf}}[\mathrm{ppm}]$ & $\mathrm{C}_{\mathrm{H} 0}-\mathrm{C}_{\mathrm{Hf}}[\mathrm{ppm}]$ \\
\hline 42CrMo4_700 & 201 & 1.2 & 0.4 & 0.8 \\
\hline 42CrMo4_650 & 246 & 1.2 & 0.7 & 0.5 \\
\hline 42CrMo4_600 & 281 & 1.4 & 0.9 & 0.5 \\
\hline 42CrMo4_550 & 307 & 1.7 & 1.4 & 0.3 \\
\hline 42CrMo4_500 & 335 & 1.9 & 1.7 & 0.2 \\
\hline 2.25Cr1Mo_690 & 170 & 0.6 & 0.2 & 0.4 \\
\hline 2.25Cr1Mo_600 & 285 & 1.3 & 0.6 & 0.7 \\
\hline 2.25Cr1MoV_720 & 200 & 4.3 & 3.9 & 0.4 \\
\hline 2.25Cr1MoV_650 & 262 & 3.8 & 3.4 & 0.4 \\
\hline
\end{tabular}

\subsection{Fracture toughness}

Fracture toughness results with respect to the steel grades tested without hydrogen are shown in Table 5. The potential law from the fitted experimental data, $\mathrm{J}=\mathrm{C}_{1} \Delta \mathrm{a}^{\mathrm{C} 2}$, is also included in this table and allows us to estimate the $\mathrm{J}$ value for any value of crack growth. As expected, the value of $\mathrm{J}_{0.2 / \mathrm{BL}}$ ( $\mathrm{J}$ crack growth initiation value determined for a $0.2 \mathrm{~mm}$ crack growth offset to the blunting line) decreases with decreasing tempering temperature (higher yield strength and ultimate tensile strength), as does the $\mathrm{C}_{2}$ parameter, which leads to a flatter crack propagation curve. In all cases, the operative fracture micromechanism was fully ductile microvoid coalescence (MVC), as can be seen in Fig. 2 for the $42 \mathrm{CrMo} 4$ specimens respectively tempered at the highest and lowest temperatures, 700 and $500^{\circ} \mathrm{C}$.

Table 5. Elasto-plastic fracture toughness results. CrMo and CrMoV steel grades. Uncharged specimens.

\begin{tabular}{|c|c|c|c|c|c|}
\hline \multirow{2}{*}{ Steel Grade } & \multirow{2}{*}{$\begin{array}{c}\sigma_{\mathrm{ys}} \\
{[\mathrm{MPa}]}\end{array}$} & $\begin{array}{c}\sigma_{\mathrm{uts}} \\
{[\mathrm{MPa}]}\end{array}$ & \multirow{2}{*}{$\begin{array}{c}\mathrm{J}_{0.2 / \mathrm{BL}} \\
{\left[\mathrm{kJ} / \mathrm{m}^{2}\right]}\end{array}$} & \multicolumn{2}{|c|}{$\mathrm{J}=\mathrm{C}_{1} \Delta \mathrm{a}^{\mathrm{C} 2}$} \\
\hline 42CrMo4_700 & 622 & 710 & 580 & 739 & 0.54 \\
\hline 42CrMo4_650 & 820 & 905 & 396 & 670 & 0.62 \\
\hline 42CrMo4_600 & 880 & 985 & 292 & 456 & 0.43 \\
\hline 42CrMo4_550 & 1023 & 1113 & 280 & 455 & 0.48 \\
\hline 42CrMo4_500 & 1086 & 1198 & 249 & 369 & 0.33 \\
\hline 2.25Cr1Mo_690 & 430 & 580 & 904 & 867 & 0.60 \\
\hline 2.25Cr1Mo_600 & 761 & 887 & 743 & 941 & 0.54 \\
\hline 2.25Cr1MoV_720 & 567 & 714 & 672 & 847 & 0.71 \\
\hline 2.25Cr1MoV_650 & 667 & 829 & 533 & 767 & 0.62 \\
\hline
\end{tabular}




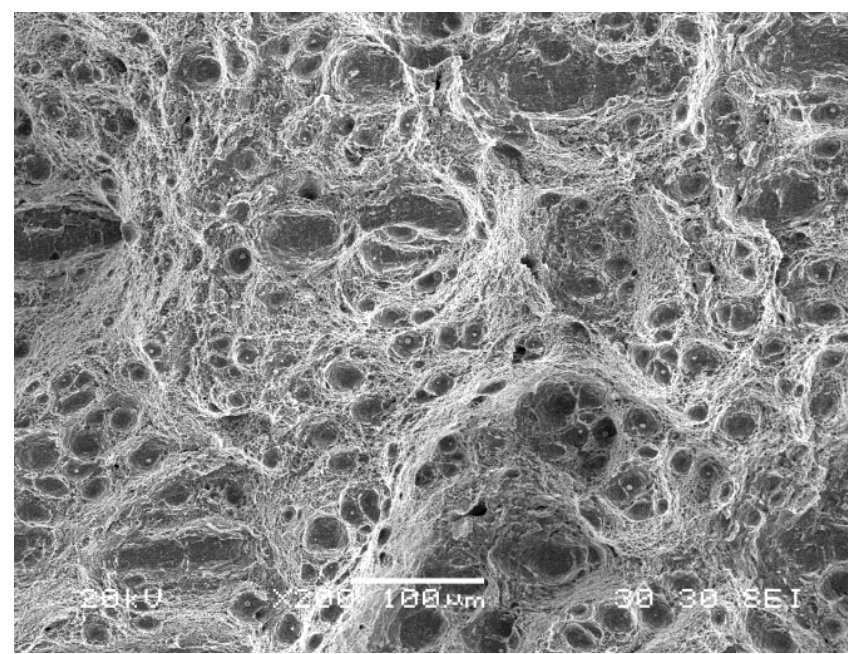

(a)

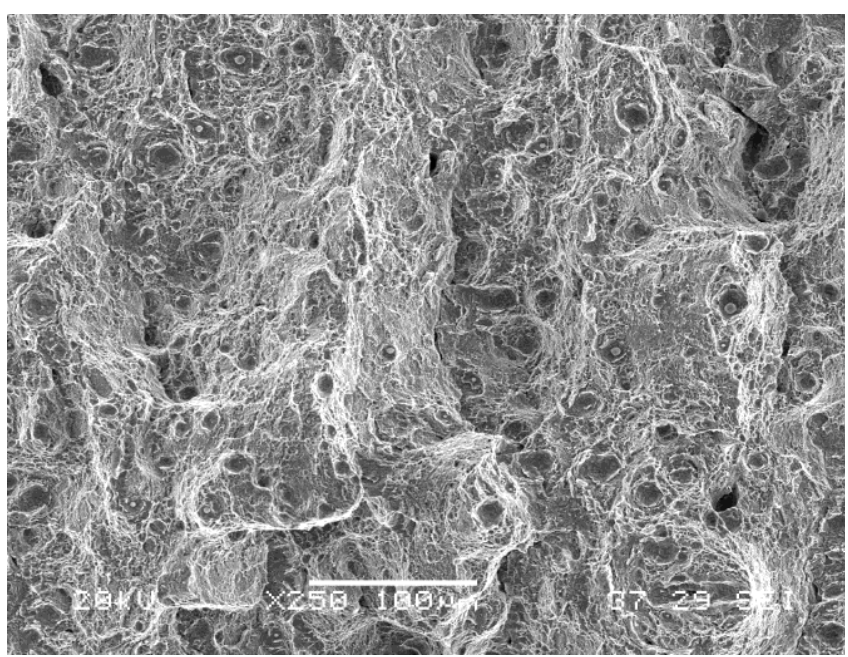

(b)

Figure 2. Fracture surfaces on uncharged CT specimens of (a) 42CrMo4_700 and (b) 42CrMo4_500.

Tables 6 and 7 show the results of all the fracture toughness tests carried out on uncharged and on hydrogen precharged specimens under different displacement rates. Additionally, the required $\mathbf{J}$ value for the initial crack to grow 1 $\mathrm{mm}$, from 0.2 to $1.2 \mathrm{~mm}, \Delta \mathrm{J}_{0.2 \rightarrow 1.2 / \mathrm{BL}}$, the embrittlement indexes and the operative fracture micromechanisms (by order of importance) are also given.

Table 6. Results of fracture toughness tests performed on the 42CrMo4 steel grade, uncharged and hydrogen pre-charged, loaded at different displacement rates $\left(J_{Q}=K_{Q}^{2}\left(1-v^{2}\right) / E\right)$. *MVC: microvoid coalescence; PRHIC: plasticity-related hydrogen induced cracking; IG: intergranular (in order of importance).

\begin{tabular}{|c|c|c|c|c|c|c|c|c|}
\hline \multicolumn{2}{|c|}{$\begin{array}{c}\text { Steel } \\
\text { Grade }\end{array}$} & $\begin{array}{c}\mathrm{V}_{\text {test }} \\
{[\mathrm{mm} / \mathrm{min}]}\end{array}$ & $\begin{array}{c}\mathrm{J}_{0.2 / \mathrm{BL}} \\
{\left[\mathrm{kJ} / \mathrm{m}^{2}\right]}\end{array}$ & $\begin{array}{c}\mathrm{J}_{1.2 / \mathrm{BL}} \\
{\left[\mathrm{kJ} / \mathrm{m}^{2}\right]}\end{array}$ & $\begin{array}{c}\Delta \mathrm{J}_{0.2 \rightarrow 1.2 / \mathrm{BL}} \\
{\left[\mathrm{kJ} / \mathrm{m}^{2}\right]}\end{array}$ & $\begin{array}{c}\mathrm{EI}\left(\mathrm{J}_{0.2 / \mathrm{BL}}\right) \\
{[\%]}\end{array}$ & $\begin{array}{c}\mathrm{EI}\left(\Delta \mathrm{J}_{0.2 \rightarrow 1.2 / \mathrm{BL}}\right) \\
{[\%]}\end{array}$ & $\begin{array}{c}* \text { Fracture } \\
\text { Micromechanisms }\end{array}$ \\
\hline \multirow{21}{*}{ 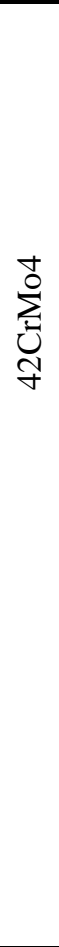 } & \multirow{4}{*}{700} & 1.00 & 580 & 1073 & 493 & - & - & MVC \\
\hline & & 1.00 & 350 & 724 & 374 & 40 & 24 & MVC+PRHIC \\
\hline & & 0.10 & 380 & 757 & 377 & 34 & 24 & MVC+PRHIC \\
\hline & & 0.01 & 345 & 585 & 240 & 41 & 51 & MVC+PRHIC \\
\hline & \multirow{4}{*}{650} & 1.00 & 396 & 950 & 454 & - & - & MVC \\
\hline & & 1.00 & 303 & 600 & 297 & 23 & 35 & MVC+PRHIC \\
\hline & & 0.10 & 273 & 560 & 287 & 31 & 37 & MVC+PRHIC \\
\hline & & 0.01 & 249 & 505 & 256 & 37 & 44 & PRHIC \\
\hline & \multirow{4}{*}{600} & 1.00 & 292 & 545 & 253 & - & - & MVC \\
\hline & & 1.00 & 205 & 340 & 135 & 30 & 47 & MVC+PRHIC \\
\hline & & 0.10 & 191 & 260 & 69 & 35 & 73 & $\mathrm{MVC}+\mathrm{PRHIC}+\mathrm{IG}$ \\
\hline & & 0.01 & 53 & 120 & 67 & 82 & 74 & PRHIC+IG \\
\hline & $\mathrm{T}_{\mathrm{rev}}$ & $\begin{array}{c}\mathrm{V}_{\text {test }} \\
{[\mathrm{mm} / \mathrm{min}]}\end{array}$ & $\begin{array}{l}\mathrm{P}_{\mathrm{Q}} \\
{[\mathrm{N}]}\end{array}$ & $\begin{array}{c}\mathrm{K}_{\mathrm{Q}} \\
{\left[\mathrm{MPam}^{-1 / 2}\right]}\end{array}$ & $\begin{array}{c}\mathrm{J}_{\mathrm{Q}} \\
{\left[\mathrm{kJ} / \mathrm{m}^{2}\right]}\end{array}$ & $\begin{array}{c}\mathrm{EI}\left(\mathrm{P}_{\mathrm{Q}}\right) \\
{[\%]}\end{array}$ & $\begin{array}{c}\mathrm{EI}\left(\mathrm{J}_{\mathrm{Q}}\right) \\
{[\%]}\end{array}$ & $\begin{array}{c}* \text { Fracture } \\
\text { Micromechanisms }\end{array}$ \\
\hline & \multirow{4}{*}{550} & 0.100 & 30750 & 143 & 89 & - & - & MVC \\
\hline & & 0.100 & 22404 & 107 & 50 & 37 & 44 & $\mathrm{MVC}+\mathrm{PRHIC}+\mathrm{IG}$ \\
\hline & & 0.010 & 12500 & 66 & 19 & 59 & 79 & PRHIC+IG+MVC \\
\hline & & 0.001 & 8900 & 43 & 8 & 71 & 91 & IG+PRHIC \\
\hline & \multirow{4}{*}{500} & 0.100 & 41892 & 157 & 112 & - & - & MVC \\
\hline & & 0.100 & 23262 & 85 & 32 & 45 & 71 & MVC+IG+PRHIC \\
\hline & & 0.010 & 12611 & 43 & 8 & 70 & 93 & IG+PRHIC \\
\hline & & 0.001 & 7416 & 17 & 1 & 82 & 99 & IG+PRHIC \\
\hline
\end{tabular}


Table 7. Results of fracture toughness tests performed on the 2.25Cr1Mo and 2.25Cr1MoV steel grades, uncharged and hydrogen pre-charged, loaded at different displacement rates. ${ }^{*} M V C:$ microvoid coalescence; PRHIC: plasticity-related hydrogen induced cracking; IG: intergranular (in order of importance).

\begin{tabular}{|c|c|c|c|c|c|c|c|c|}
\hline \multicolumn{2}{|c|}{$\begin{array}{l}\text { Steel } \\
\text { Grade }\end{array}$} & $\begin{array}{c}\mathrm{V}_{\text {test }} \\
{[\mathrm{mm} / \mathrm{min}]}\end{array}$ & $\begin{array}{c}\mathrm{J}_{0.2 / \mathrm{BL}} \\
{\left[\mathrm{kJ} / \mathrm{m}^{2}\right]}\end{array}$ & $\begin{array}{c}\mathrm{J}_{1.2 / \mathrm{BL}} \\
{\left[\mathrm{kJ} / \mathrm{m}^{2}\right]}\end{array}$ & $\begin{array}{c}\Delta \mathrm{J}_{0.2 \rightarrow 1.2 / \mathrm{BL}} \\
{\left[\mathrm{kJ} / \mathrm{m}^{2}\right]}\end{array}$ & $\begin{array}{c}\mathrm{EI}\left(\mathrm{J}_{0.2 / \mathrm{BL}}\right) \\
{[\%]}\end{array}$ & $\begin{array}{c}\mathrm{EI}\left(\Delta \mathrm{J}_{0.2 \rightarrow 1.2 / \mathrm{BL}}\right) \\
{[\%]}\end{array}$ & $\begin{array}{c}\text { *Fracture } \\
\text { Micromechanisms }\end{array}$ \\
\hline \multirow{8}{*}{ 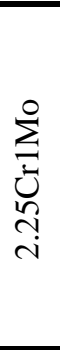 } & \multirow{4}{*}{690} & 1.00 & 904 & 1560 & 656 & - & - & MVC \\
\hline & & 1.00 & 502 & 1062 & 560 & 43 & 15 & MVC+PRHIC \\
\hline & & 0.10 & 602 & 1240 & 638 & 33 & 3 & MVC+PRHIC \\
\hline & & 0.01 & 465 & 701 & 236 & 49 & 64 & $\mathrm{MVC}+\mathrm{PRHIC}$ \\
\hline & \multirow{4}{*}{600} & 1.00 & 743 & 1410 & 667 & - & - & MVC \\
\hline & & 1.00 & 389 & 786 & 397 & 47 & 40 & MVC \\
\hline & & 0.10 & 394 & 680 & 286 & 47 & 57 & MVC+PRHIC \\
\hline & & 0.01 & 294 & 584 & 290 & 60 & 57 & PRHIC+IG \\
\hline \multirow{8}{*}{ 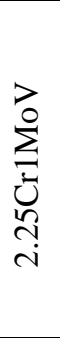 } & \multirow{4}{*}{720} & 1.00 & 672 & 1600 & 928 & - & - & MVC \\
\hline & & 1.00 & 542 & 1280 & 738 & 19 & 20 & MVC \\
\hline & & 0.10 & 420 & 880 & 460 & 38 & 54 & MVC \\
\hline & & 0.01 & 448 & 784 & 336 & 37 & 64 & MVC \\
\hline & \multirow{4}{*}{650} & 1.00 & 533 & 1188 & 655 & - & - & MVC \\
\hline & & 1.00 & 403 & 660 & 257 & 24 & 61 & MVC \\
\hline & & 0.10 & 341 & 637 & 296 & 36 & 57 & MVC \\
\hline & & 0.01 & 314 & 580 & 266 & 41 & 59 & MVC \\
\hline
\end{tabular}

The fracture toughness-crack growth $(\mathrm{J}-\Delta \mathrm{a})$ curves of the $42 \mathrm{CrMo} 4$ grade tempered at the highest temperature $\left(700^{\circ} \mathrm{C}\right)$ with the lowest yield strength, corresponding to uncharged and $\mathrm{H}$-charged specimens, at $1,0.1$ and $0.01 \mathrm{~mm} / \mathrm{min}$, are shown in Fig. 3. The effect of hydrogen is noticeable in all cases, giving rise to a clear decrease in $\mathrm{J}_{0.2 / \mathrm{BL}}$ and $\mathrm{J}_{1.2 / \mathrm{BL}}$. Maximum embrittlement occurred under the lowest displacement rate, $0.01 \mathrm{~mm} / \mathrm{min}$. However, a decrease in fracture toughness when decreasing the displacement rate was noted in all the tested grades (see Tables 6 and 7), as the accumulation of hydrogen atoms in the process zone located ahead of the crack tip of the CT fracture specimen (trapped by dislocations in the plastic zone and also driven by the high hydrostatic stress existing at the crack front) increases due to the availability of longer diffusion times, giving rise to the embrittlement phenomenon. It is well known that mobile hydrogen atoms move due to being attracted by local hydrostatic stress, $\sigma_{\mathrm{h}}$, which according to continuum plasticity theory reaches a maximum at a distance $\mathrm{x}$ from the crack tip, $\mathrm{x}=\mathrm{J} / \sigma_{\mathrm{ys}}$. Moreover, local strain exhibits a singularity at the crack tip, reaching very high values $\left(\varepsilon_{\mathrm{eq}}>10 \%\right)$ at approximately half this distance $\left(\mathrm{J} / 2 \sigma_{\mathrm{ys}}\right)$, where the dislocation density multiplies, giving rise to high local hydrogen accumulation [26, 27].

The fracture surface of the specimen tested under the lowest displacement rate can be seen in Fig. 4(a). Two different regions can be distinguished: Region 1, with an extension of between $250-300 \mu \mathrm{m}$, corresponds to the crack initiation phase, while Region 2 corresponds to the propagation phase. Taking into account the values of $\mathrm{J}_{0.2 / \mathrm{BL}}$ measured in this specimen $\left(345 \mathrm{~kJ} / \mathrm{m}^{2}\right)$ and the yield strength of this steel $(622 \mathrm{MPa})$, the extension of the strained region where hydrogen accumulates is $280 \mu \mathrm{m}$. Region 1, which can be seen in more detail in Fig. 4(b), exhibits the appearance of a transgranular fracture surface or quasi-cleavage, usually referred to as plasticity-related hydrogen induced cracking (PRHIC) in martensitic steels [28]. The PRHIC mechanism was first described by Takeda and McMahon [29] in reference to the fracture mechanism observed in a low alloy quenched and tempered steel in hydrogen gas. It is sometimes called tearing topography surface or TTS, which is described as a fracture surface characterised by ductile micro-plastic tearing on a very fine scale, along martensite block and packet interphases [28, 30]. The size of the characteristic features observed in Fig. 4(b) is comparable to the microstructure units (martensite blocks and packets); hence, hydrogen accumulation promotes plastic deformation and final decohesion of these interphases (HEDE, hydrogen-enhanced decohesion). A mixed micromechanism is observed in Region 2 (Fig. 4(a)), with areas of MVC and PRHIC, in the latter case inside the expanded microvoids caused by a local increase in plasticity due to solute hydrogen, which facilitates the movement of dislocations (hydrogen-enhanced localized plasticity, HELP) [10, 31]. As the applied $\mathrm{J}$ increases, the plastic zone extends, diffusible hydrogen redistributes into a larger volume and hence, the total local 
hydrogen content in the process zone decreases and PRHIC is no longer the only failure micomechanism (MVC also appears).

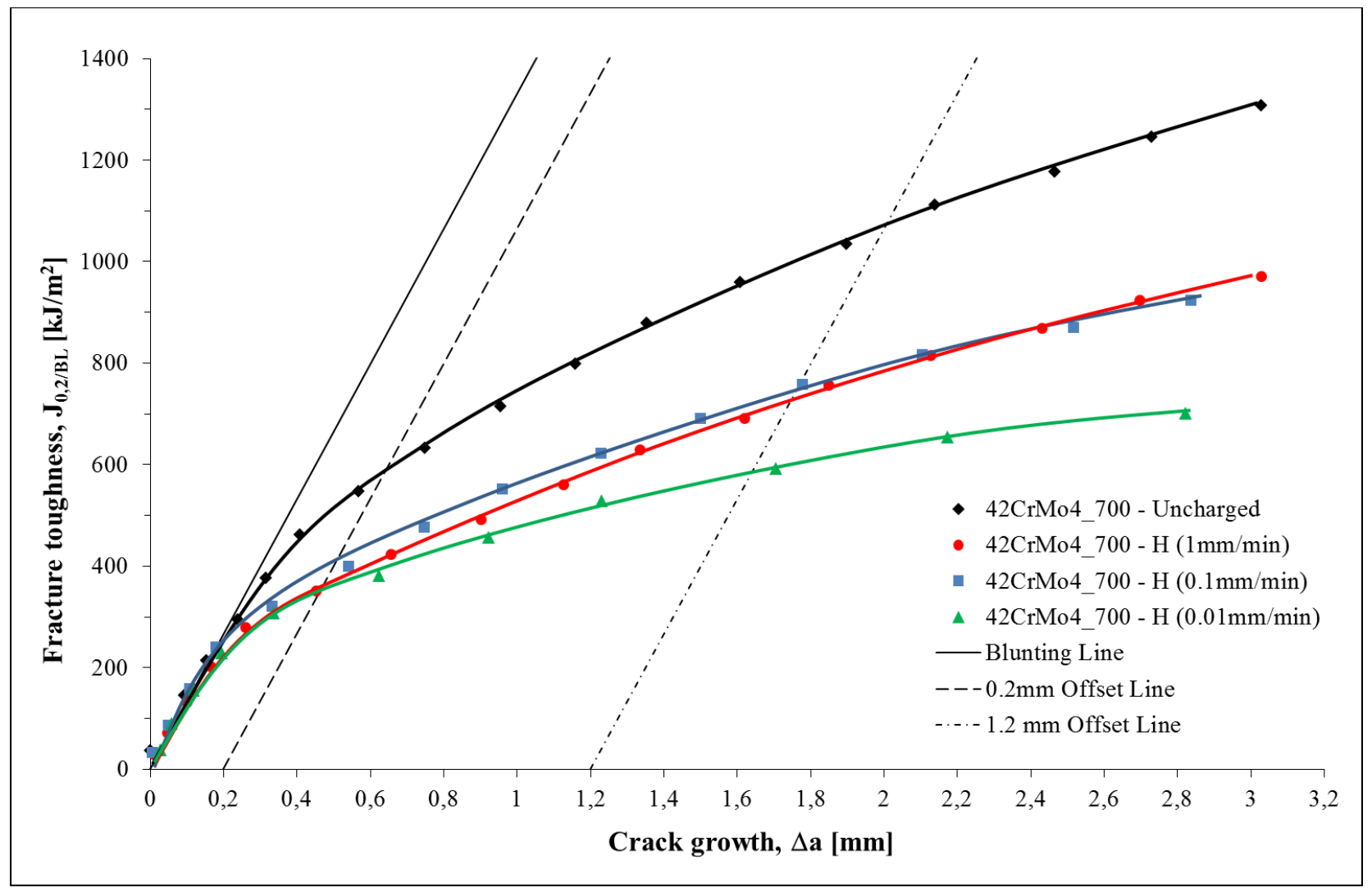

Figure 3. J-Aa curves of uncharged and H-charged specimens of 42CrMo4_700 grade.

The embrittlement indexes and predominant fracture micromechanisms corresponding to the steel grade quenched and tempered at $650^{\circ} \mathrm{C}$ for the different displacement rates, also shown in Table 6, are not so different from those observed in the $700^{\circ} \mathrm{C}$ tempered grade. As can be seen in Fig. 4(c) and (d), the fracture micromechanisms evolved from a fully ductile mechanism (MVC), in the absence of hydrogen, to PRHIC, when tested under internal hydrogen at the lowest displacement rate. Mixtures of MVC and PRHIC micromechanisms were observed in hydrogen pre-charged specimens tested at intermediate displacement rates (Table 6), as the available time for hydrogen diffusion decreased and hydrogen accumulation within the process zones was lower.

The hydrogen pre-charged steel grade quenched and tempered at $600^{\circ} \mathrm{C}$ tested at $0.1 \mathrm{~mm} / \mathrm{min}$ already shows traces of IG fracture that finally, when tested at an even lower displacement rate, gives rise to a mixture of PRHIC and IG, as can be seen in Fig. 4(e) and (f). The higher initial and final hydrogen contents measured in this grade (Table 4), along with its higher yield strength $\left(\sigma_{\mathrm{h}} \sim 2.5 \sigma_{\mathrm{ys}}\right.$, according to continuum plasticity theory), provides greater hydrogen accumulation within the process zone, thus explaining this behaviour.

Finally, the extreme brittleness of the $\mathrm{H}$-charged $42 \mathrm{CrMo} 4$ steel grades quenched and tempered at the lowest temperatures $\left(550\right.$ and $500^{\circ} \mathrm{C}$ ) precluded obtaining $\mathrm{J}-\Delta \mathrm{a}$ curves, so $\mathrm{K}_{\mathrm{Q}}$ at instability (maximum load, $\mathrm{P}_{\mathrm{Q}}$ ) was used as a characteristic fracture toughness parameter. The Load-COD displacement curves of the steel grade quenched and tempered at the lowest temperature, $500^{\circ} \mathrm{C}$, are plotted in Fig. 5(a). In the test carried out at $0.001 \mathrm{~mm} / \mathrm{min}$, the deleterious effects of hydrogen are noteworthy: the load, $\mathrm{P}_{\mathrm{Q}}$, drops over $80 \%$ and the embrittlement index relative to $\mathrm{J}_{\mathrm{Q}}$ is practically equal to $100 \%$. With regard to the fracture surfaces, as the displacement rate decreases, a clear evolution can be appreciated in the fracture micromechanisms. In this case, starting from MVC for the uncharged specimen, they pass through a mixture of MVC, PRHIC and IG for the charged specimen tested at $0.1 \mathrm{~mm} / \mathrm{min}$ to finish in a micromechanism mainly composed of IG fracture, with faint remnants of PRHIC features, for the lowest displacement rate, as can be observed in Fig. 4(i) and (j). Quite similar results were also obtained with the steel grade quenched and 
tempered at $550^{\circ} \mathrm{C}$ (Fig. 5(b)): in the case of the test performed at the lowest displacement rate, the predominant micromechanism is IG, with isolated regions of PRHIC, Fig. 4 (g) and (h). These two grades have much higher levels of strongly trapped hydrogen than the other $42 \mathrm{CrMo} 4$ grades and also higher yield strengths (Tables 3 and 4). As mobile hydrogen accumulates in the process zone ahead of the crack tip submitted to high hydrostatic stress, attaining a concentration related to the steel yield strength $\left(\sigma_{\mathrm{h}} \sim 2.5 \sigma_{\mathrm{ys}}\right)$, internal interphases such as prior austenitic grain joints and block and packet martensite boundaries easily fail under a relatively small local opening stress (HEDE micromechanism).

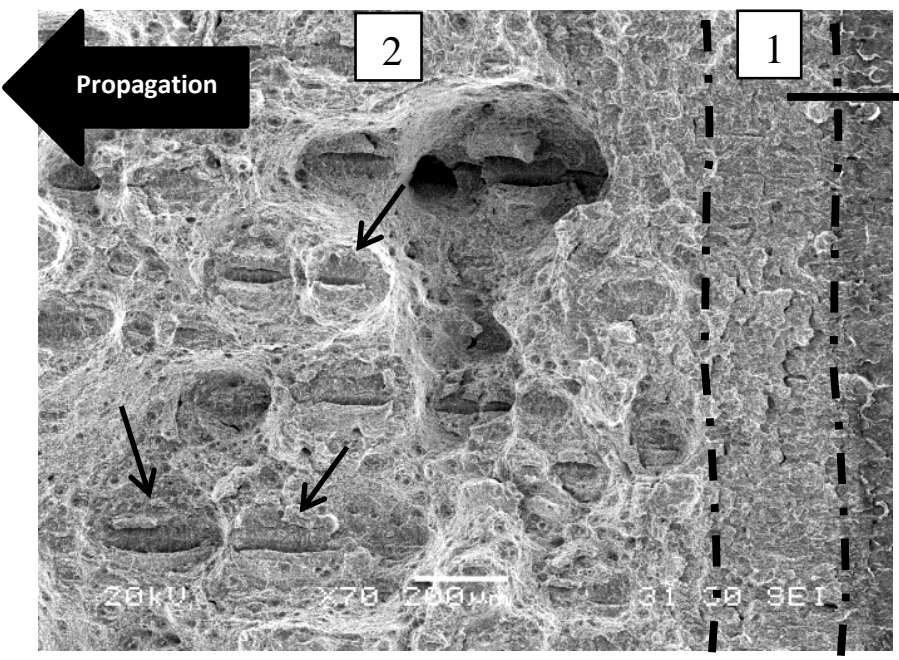

(a)

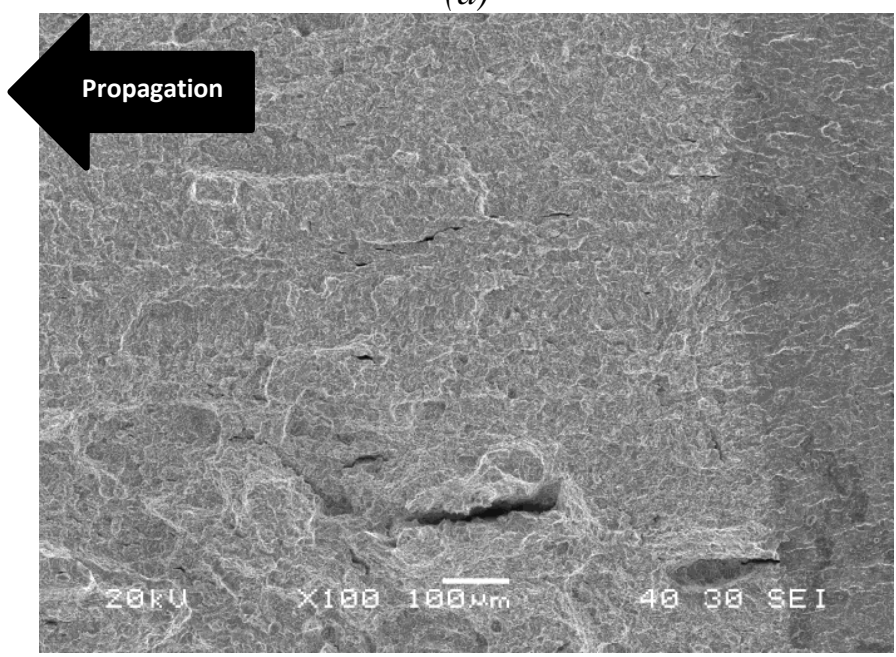

(c)

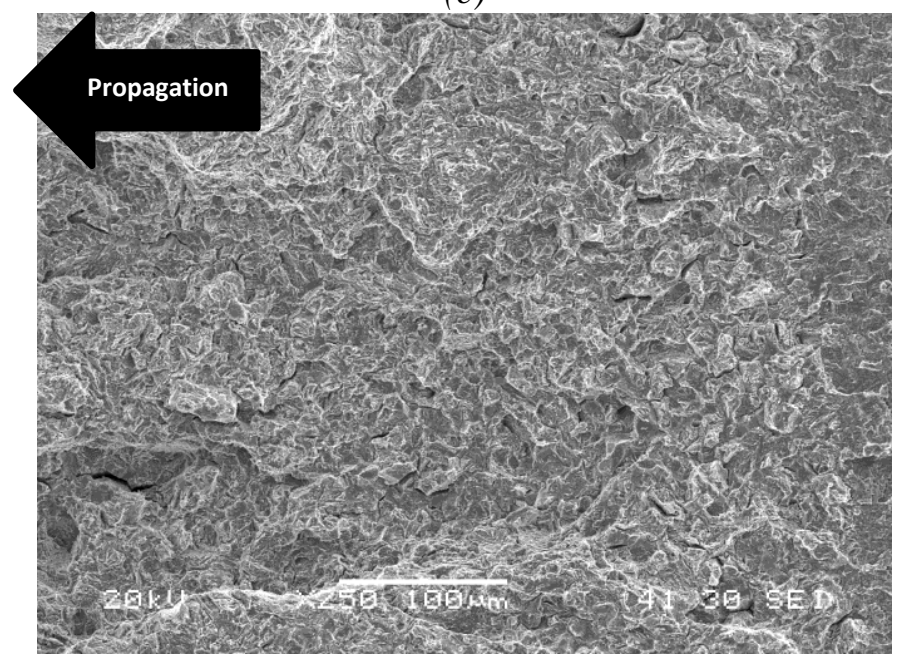

(e)

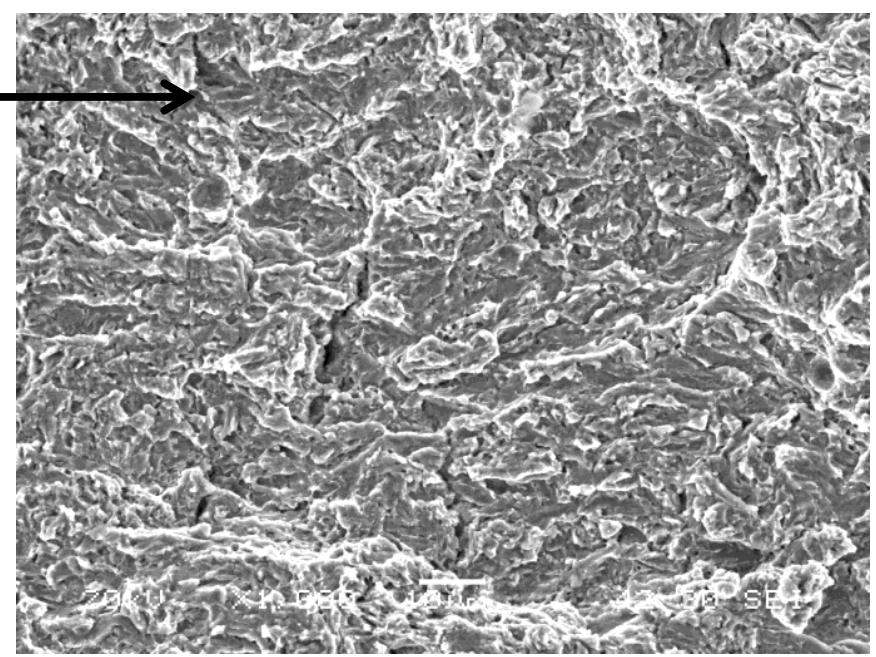

(b)

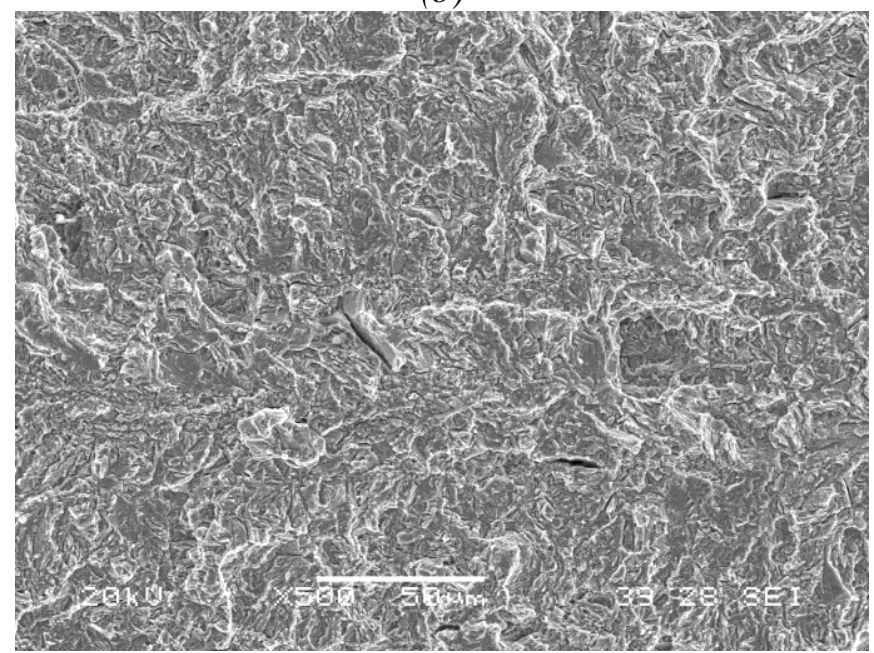

(d)

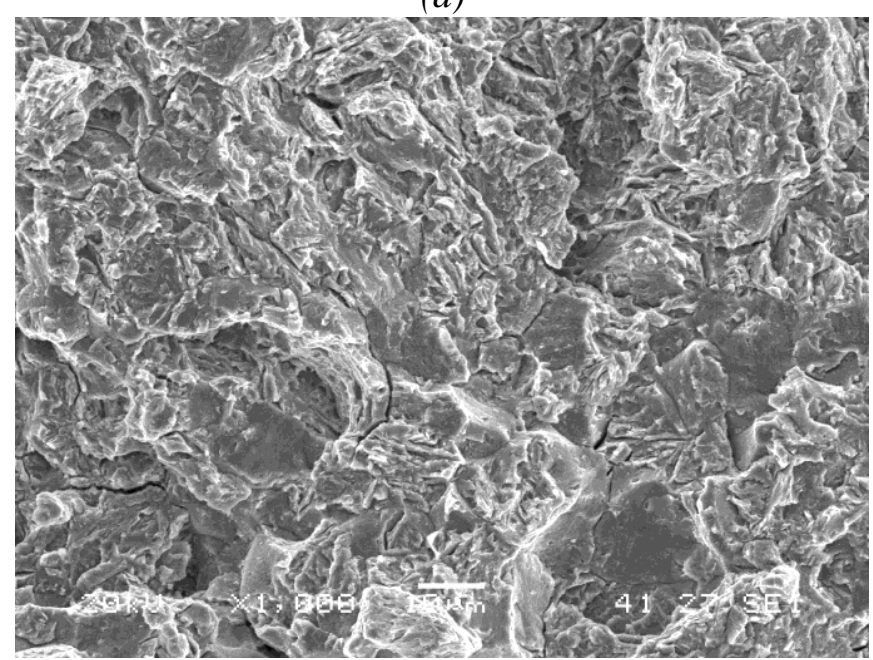

(f) 


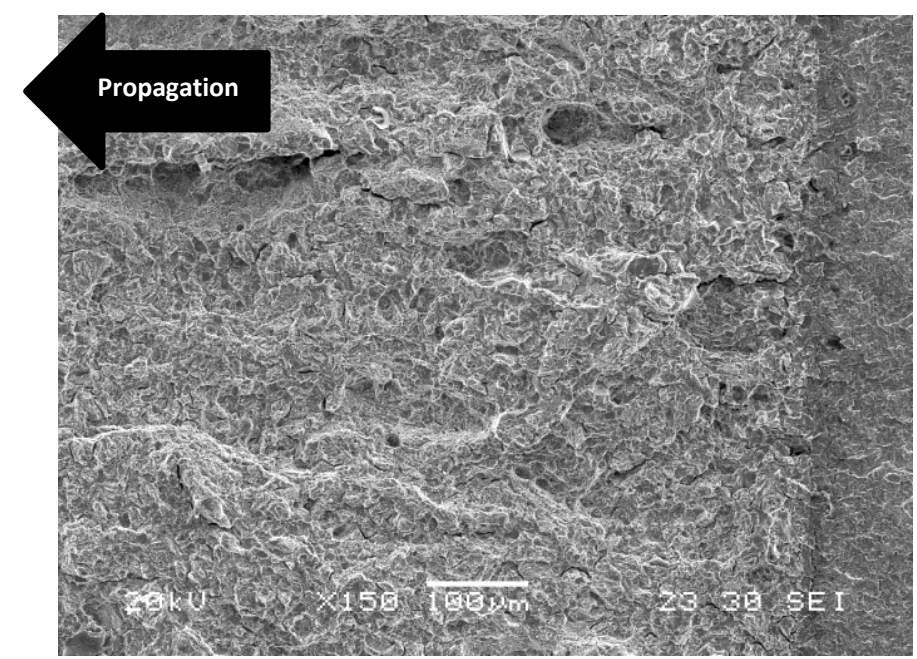

$(g)$

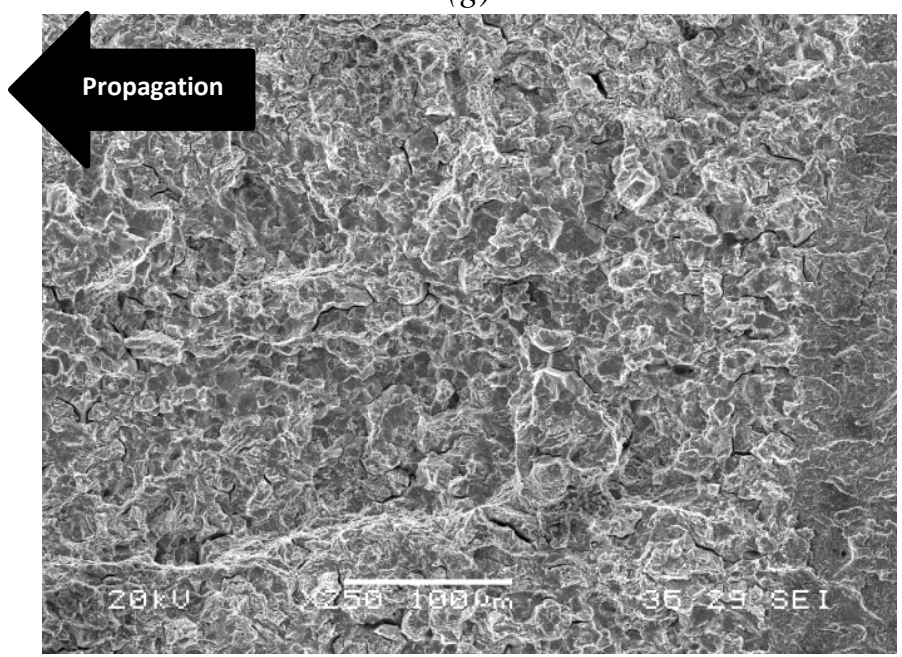

(i)

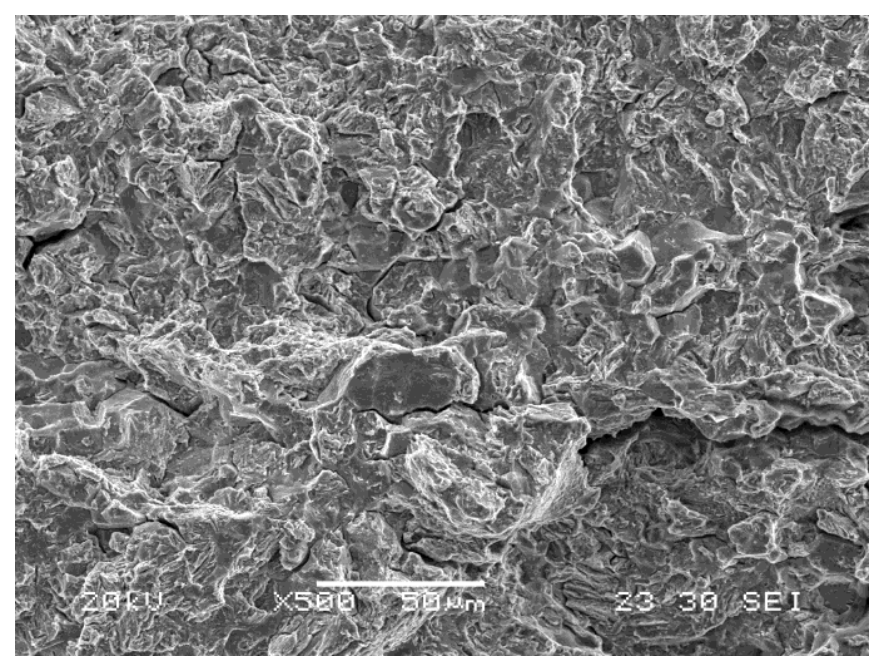

(h)

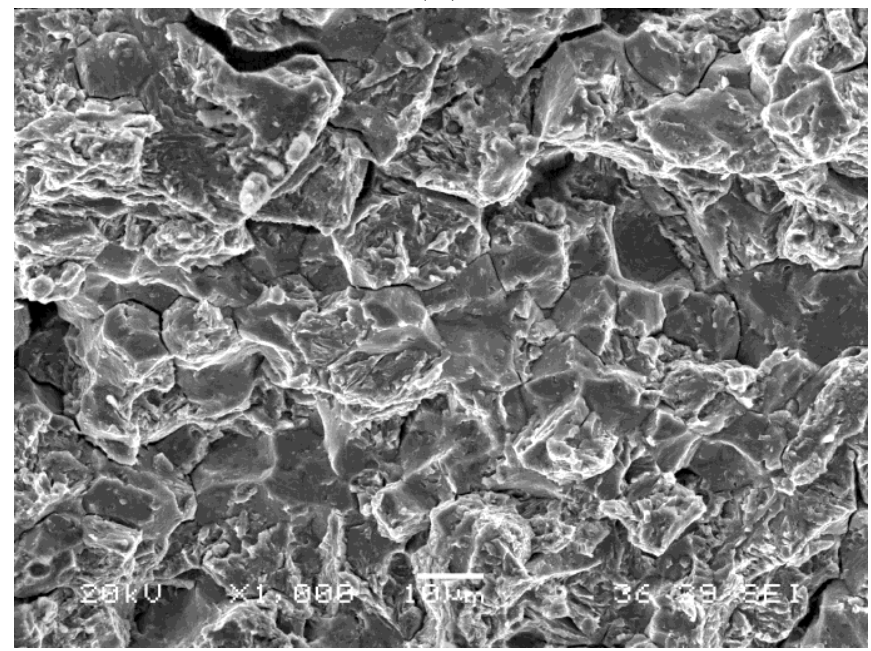

$(j)$

Figure 4. Fracture micromechanisms of $42 \mathrm{CrMo} 4$ grades tested with internal hydrogen at the lowest displacement rates.

(a) 42CrMo4_700 $(0.01 \mathrm{~mm} / \mathrm{min})$, (b) 42CrMo4_700 $(0.01 \mathrm{~mm} / \mathrm{min})$, (c) $42 \mathrm{CrMo4} 650(0.01 \mathrm{~mm} / \mathrm{min})$,

(d) 42CrMo4_650 $(0.01 \mathrm{~mm} / \mathrm{min})$, (e) 42CrMo4_600 $(0.01 \mathrm{~mm} / \mathrm{min}),(f) 42 \mathrm{CrMo} 4600(0.01 \mathrm{~mm} / \mathrm{min})$,

(g) 42CrMo4_550 $(0.001 \mathrm{~mm} / \mathrm{min})$, (h) 42CrMo4_550 $(0.001 \mathrm{~mm} / \mathrm{min}),($ i $) 42 \mathrm{CrMo} \_500(0.001 \mathrm{~mm} / \mathrm{min})$,

(j) 42CrMo4_500 $(0.001 \mathrm{~mm} / \mathrm{min})$

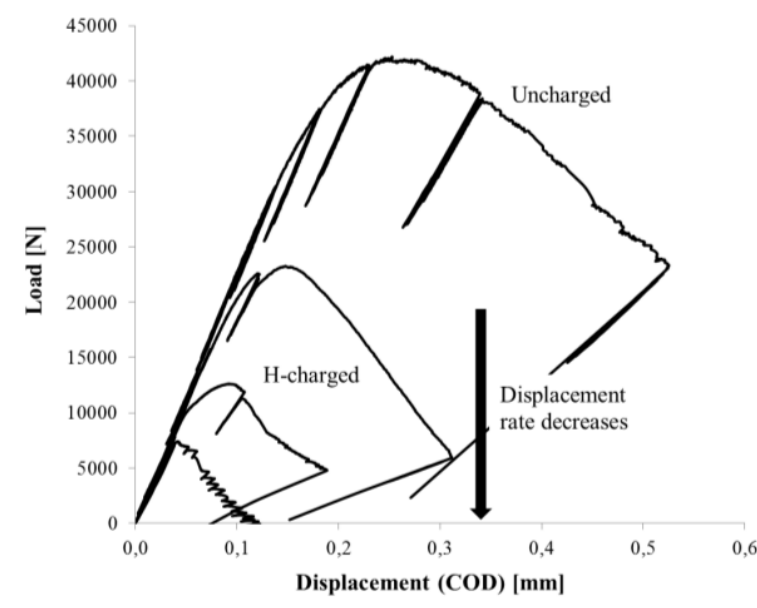

(a)

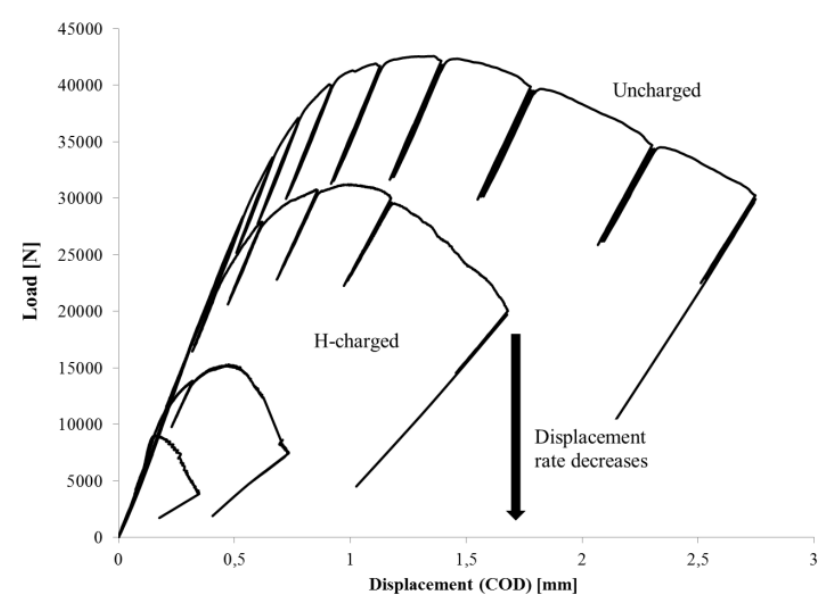

(b)

Figure 5. Load-Displacement (COD) curves corresponding to the $42 \mathrm{CrMo} 4$ steel quenched and tempered at (a) $500^{\circ} \mathrm{C}$ and (b) $550^{\circ} \mathrm{C}$. Uncharged specimen and H-charged specimens tested at $0.1,0.01$ and $0.001 \mathrm{~mm} / \mathrm{min}$.

The fracture surface of the quenched and tempered $2.25 \mathrm{Cr} 1 \mathrm{Mo}$ and $2.25 \mathrm{Cr} 1 \mathrm{MoV}$ specimens tested under internal hydrogen at the lowest displacement rate can be seen in Fig. 6. The fracture micromechanisms in $2.25 \mathrm{Cr} 1 \mathrm{Mo}$ steel 
tested with internal hydrogen resemble those already mentioned with respect to 42CrMo4 steel, with PRHIC and even some intergranular features (interphase decohesion) detected under the lowest displacement rates. Nevertheless, a unique and fully ductile fracture micromechanism (microvoid coalescence) is worth noting in all the fracture toughness tests performed with the $2.25 \mathrm{Cr} 1 \mathrm{MoV}$ grade.

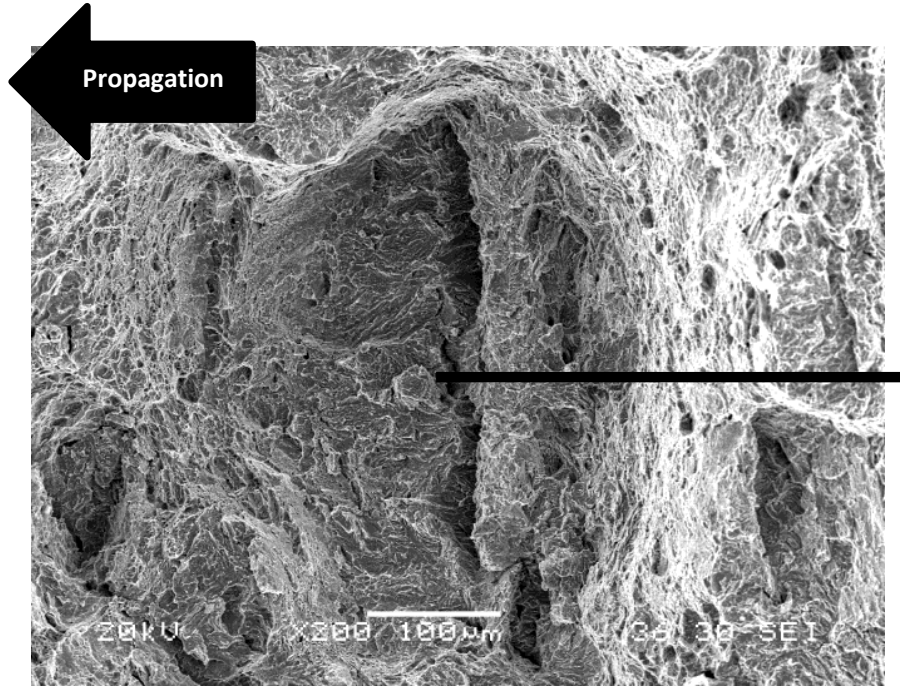

(a)

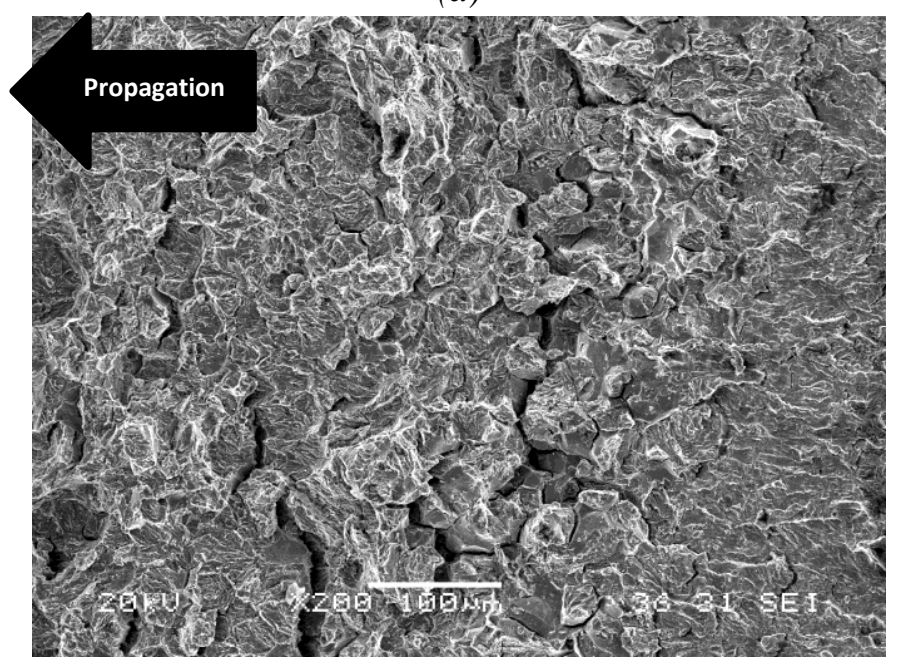

(c)

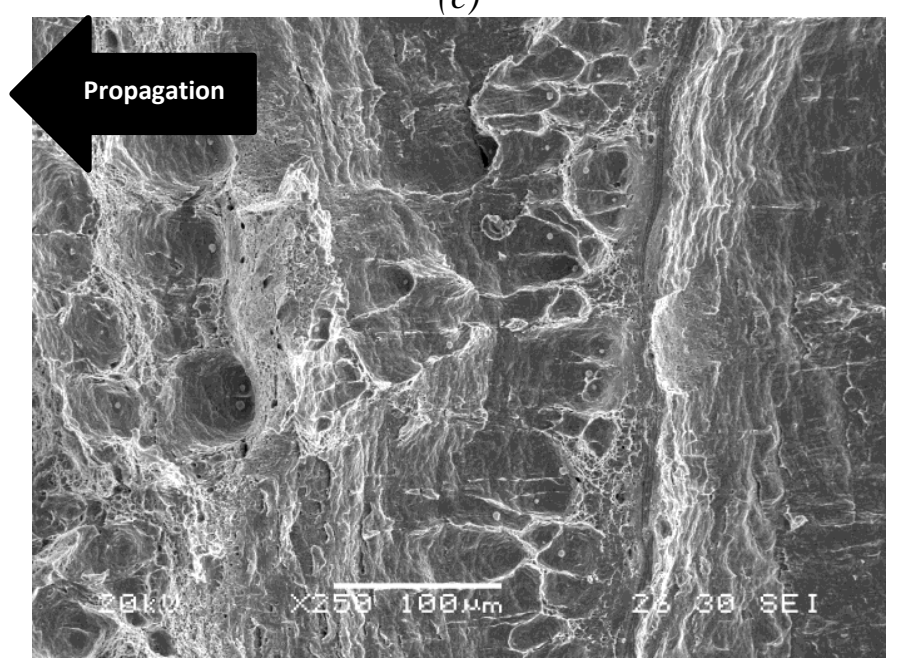

(e)

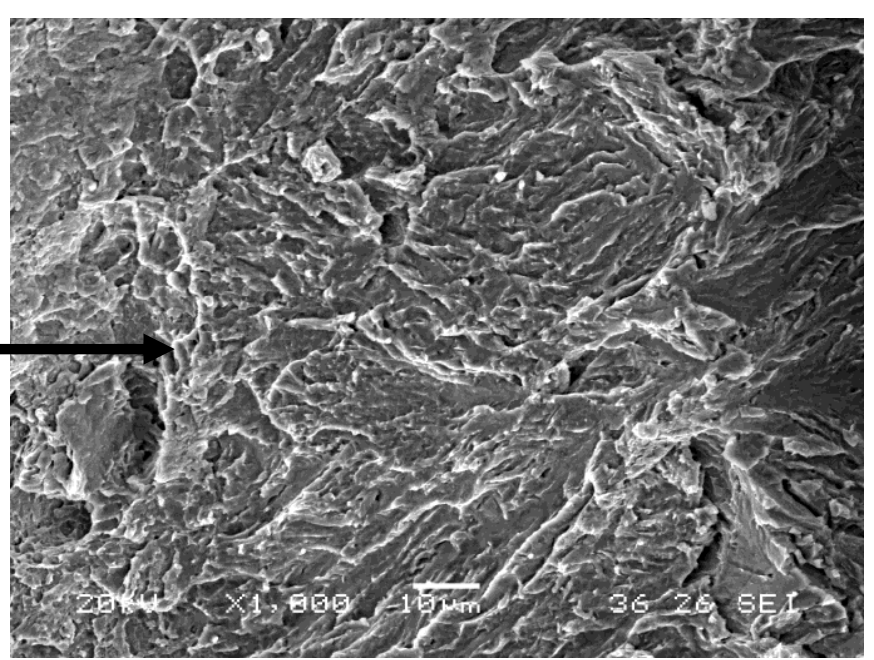

(b)

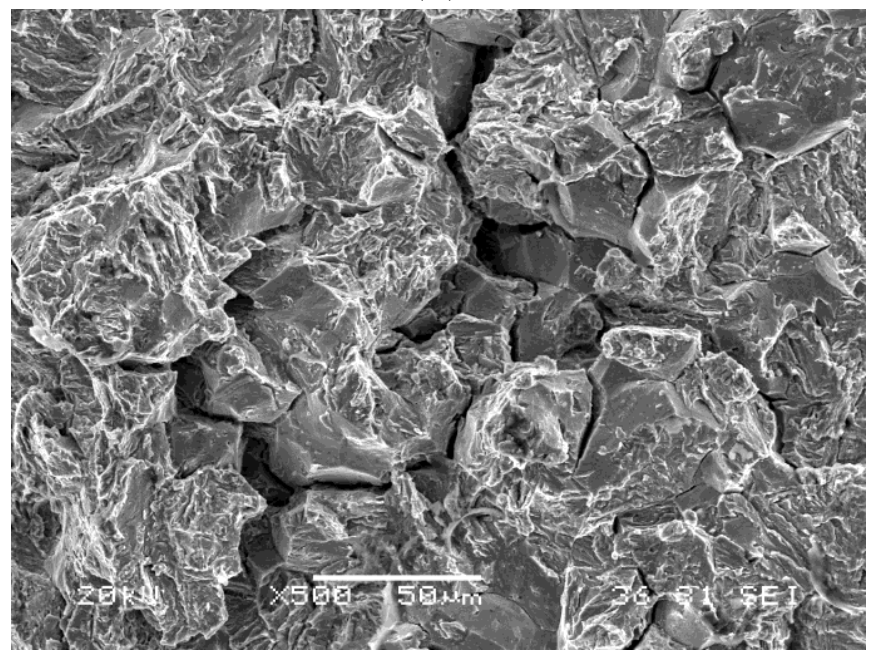

(d)

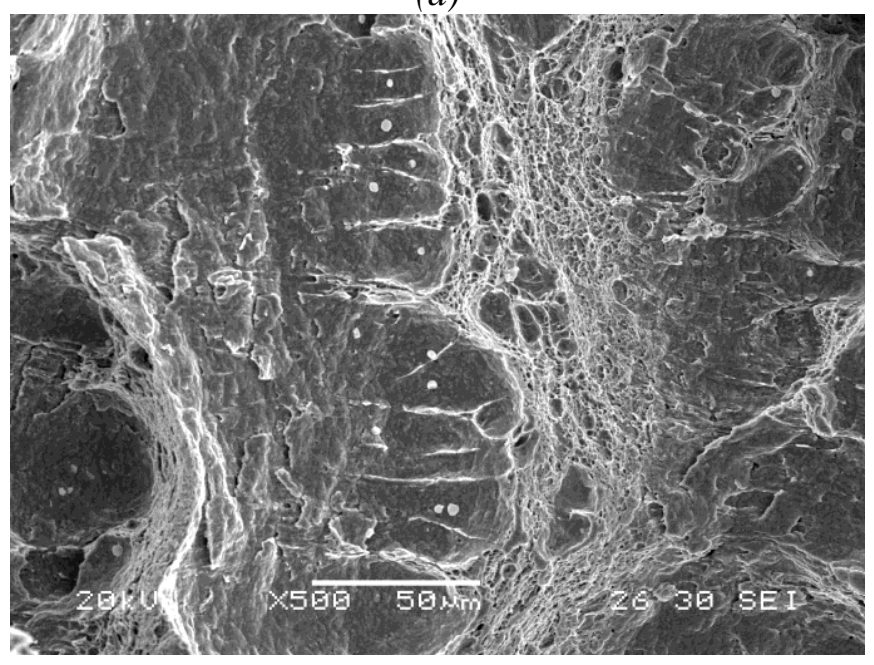

(f) 


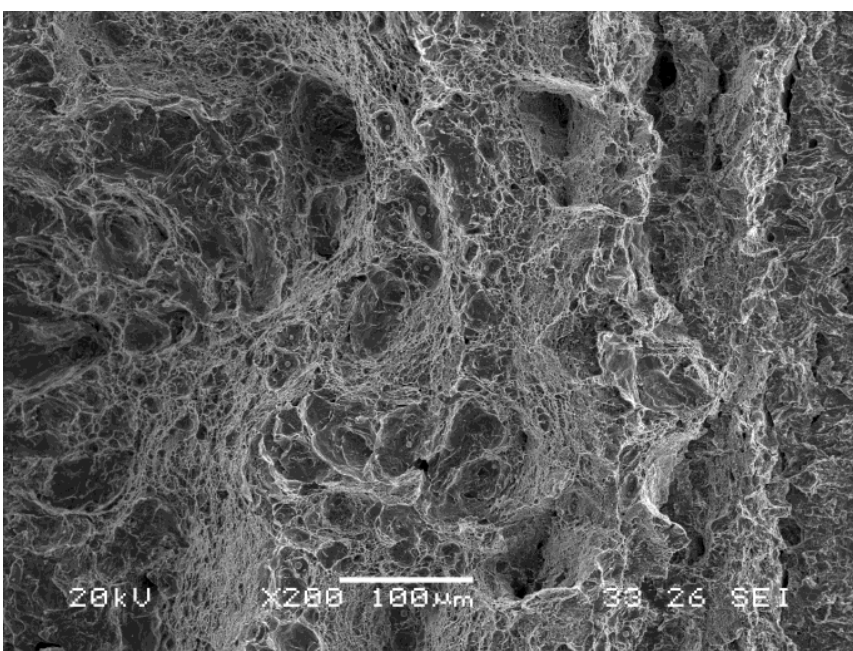

$(g)$

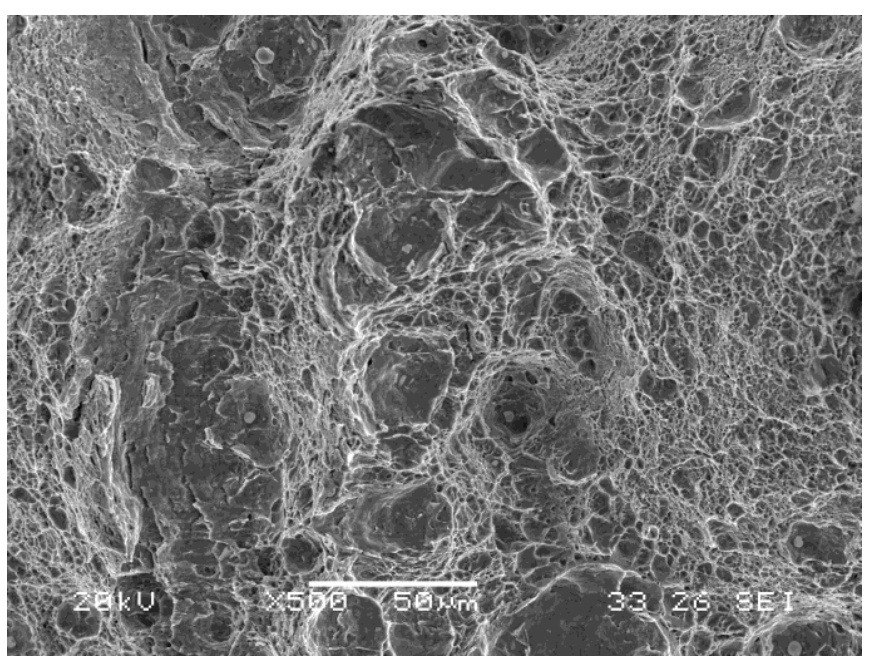

(h)

Figure 6. Fracture micromechanisms of 2.25CrlMo and 2.25Cr1MoV steel grades tested with internal hydrogen at the lowest displacement rate, $0.01 \mathrm{~mm} / \mathrm{min}$. (a) 2.25Cr1Mo_690, (b) 2.25Cr1Mo_690, (c) 2.25Cr1Mo_600, (d) 2.25Cr1Mo_600,

(e) 2.25Cr1MoV_720, (f) 2.25Cr1MoV_720, $(g) 2.25 C r 1 M o V \_650$ and $(h) 2.25 C r 1 M o V \_650$.

\section{Selection of steels to be exposed to high-pressure hydrogen gas}

Fig. 7 represents the critical stress intensity factor $\left(\mathrm{J}_{0.2 / \mathrm{BL}}\right.$ or $\left.\mathrm{J}_{\mathrm{Q}}\right)$ for the onset of crack growth under internal hydrogen and a displacement rate of $0.01 \mathrm{~mm} / \mathrm{min}$ versus the steel yield strength for the $42 \mathrm{CrMo} 4$ steel grades. The predominant fracture micromechanisms are also shown in this figure. The sudden drop in fracture toughness under internal hydrogen and a low displacement rate when intergranular failure micromechanism appears (steel grade quenched and tempered at $600^{\circ} \mathrm{C}, \sigma_{\mathrm{ys}}=880 \mathrm{MPa}$ ) are worth noting. As can be seen in Fig. 1(c), the Q+T microstructure of this steel still shows elongated carbides precipitated along prior austenite grain boundaries and packet and block martensite boundaries, resembling low tempering microstructures. These distorted internal interphases are able to trap and retain hydrogen $(0.9$ ppm $\mathrm{H}$ is strongly trapped, as can be seen in Table 4). Additionally, diffusible hydrogen $(0.5 \mathrm{ppm})$ moves and accumulates in the process zone ahead of the crack tip of the CT specimen (within the plastic zone with a high dislocation density and at the maximum hydrostatic stress region) giving rise to a HEDE failure micromechanism (hydrogen-enhanced decohesion, PRHIC and IG). However, 42CrMo4 steel quenched and tempered at 650 and $700^{\circ} \mathrm{C}$ already has sufficiently relaxed Q+T microstructures with quite uniform dispersion of globular carbides (see Fig. 1(a) and (b)), so hydrogen distributes in a more uniform manner in the crack front process region, giving rise to decohesion of packet and block martensite boundaries (PRHIC) only after significant previous plastic deformation (high fracture toughness for the onset of crack growth). 


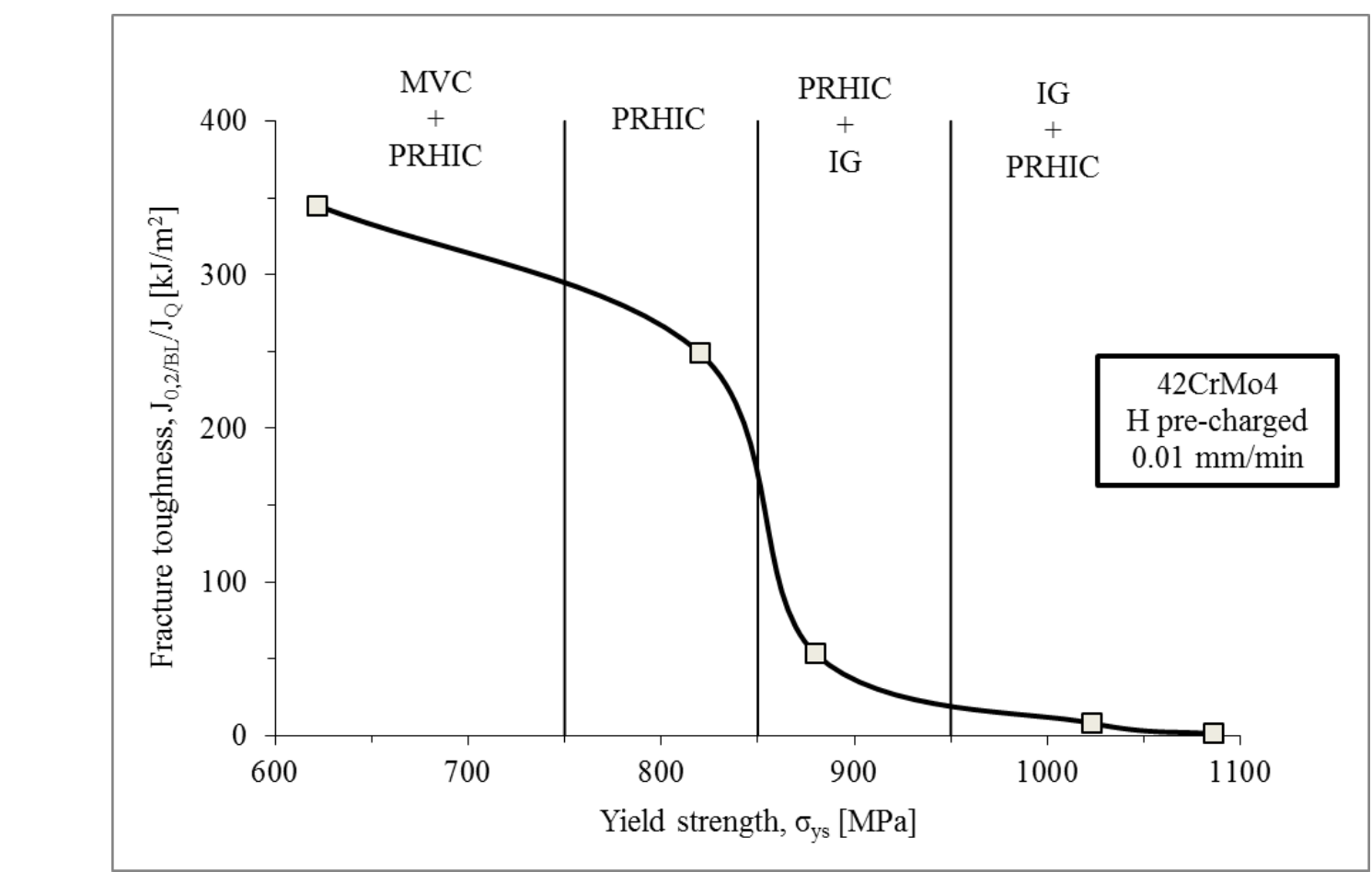

Figure 7. Fracture toughness for the onset of crack growth with internal hydrogen versus steel yield strength (42CrMo4) and predominant failure micromechanisms.

The extreme brittleness of the $\mathrm{H}$-charged $42 \mathrm{CrMo} 4$ steel grades tempered at the lowest temperatures $\left(500,550^{\circ} \mathrm{C}\right.$ and even at $600^{\circ} \mathrm{C}$ ) excludes the use of these steel grades when toughness is a design requirement.

The $\mathrm{J}$ resistance curves of the remaining quenched and tempered steel grades used in this research study under internal hydrogen tested at a low displacement rate of $0.01 \mathrm{~mm} / \mathrm{min}$ are now compared in Fig. 8. All these grades show high fracture toughness for crack propagation, PRHIC and MVC being the most important failure micromechanisms (with only small areas of IG fracture in $2.25 \mathrm{Cr} 1 \mathrm{Mo} \_600$ ). The differences in fracture toughness results and fracture micromechanisms between $42 \mathrm{CrMo} 4$ and 2.25Cr1 Mo steels are not significant. 42CrMo4 has higher carbon content and 2.25Cr1Mo higher chromium and molybdenum contents. The main differences between the two steels after quenching and high temperature tempering correspond to their carbide nature and distribution: a higher volume fraction of iron carbides for $42 \mathrm{CrMo} 4$ and chromium and molybdenum carbides in 2.25Cr1Mo [14, 32].

The high fracture toughness measured in $2.25 \mathrm{Cr} 1 \mathrm{MoV}$ steel with internal hydrogen is worth noting, being the only grade in which the presence of hydrogen did not modify the failure micromechanism (fully ductile, MVC, in all the fracture tests, as shown in Table 7). However, this steel retained much higher hydrogen contents after H-charging than the others (see Table 4). Nevertheless, in this case this hydrogen barely affects the fracture process, as it is strongly trapped by very fine sub-micrometric uniformly distributed vanadium carbides [24, 25]. 


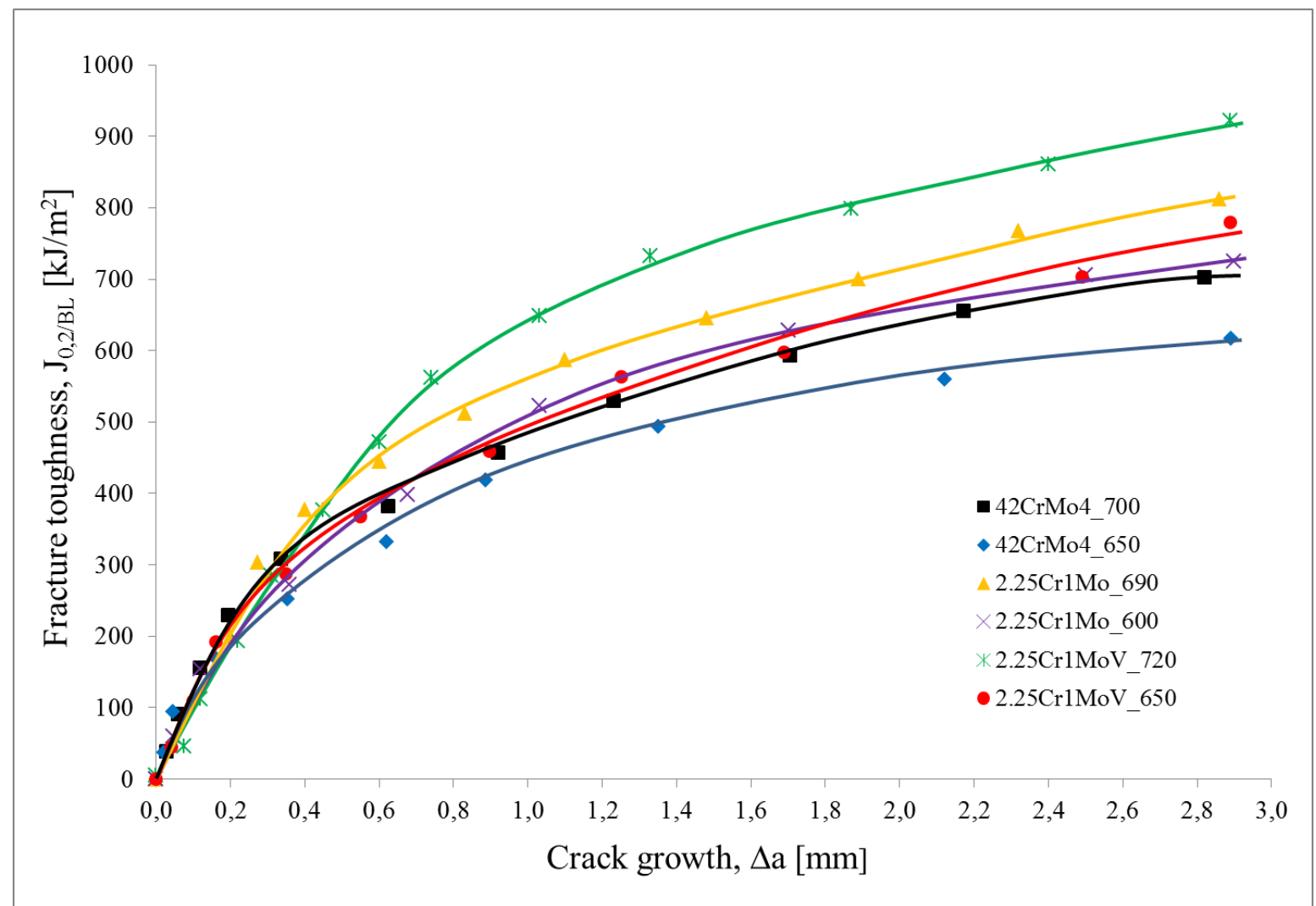

Figure 8. Fracture toughness-crack growth $(\mathrm{J}-\Delta a)$ curves corresponding to hydrogen pre-charged specimens tested at the lowest displacement rate $(0.01 \mathrm{~mm} / \mathrm{min})$.

The $\mathbf{J}$ fracture toughness of these grades for the onset of crack growth, $\mathrm{J}_{0.2 / \mathrm{BL}}$, under internal hydrogen and a displacement rate of $0.01 \mathrm{~mm} / \mathrm{min}$ is plotted in Fig. 9 versus their respective steel yield strengths. As expected, fracture toughness decreases with increasing yield strength, and a good regression with a quite high determination coefficient $\left(\mathrm{R}^{2}=0.9\right)$ being obtained, even though three different steels were employed.

Finally, it is worth noting that high fracture toughness with internal hydrogen using low displacement rates (with high hydrogen concentrations in their fracture process zones) was obtained in these quenched and tempered steel grades with yield strengths as high as $800 \mathrm{MPa}$. The use of these high strength steel grades in damage tolerant designs would allow decreasing component thickness and hence the cost of the steel used to manufacture hydrogen infrastructures such as hydrogen tanks, pipes and valves directly exposed to high-pressure hydrogen gas environments. Nonetheless, fatigue crack initiation times and fatigue crack propagation rates in the presence of hydrogen are also other important characteristics to be determined in order to properly design such infrastructures. 


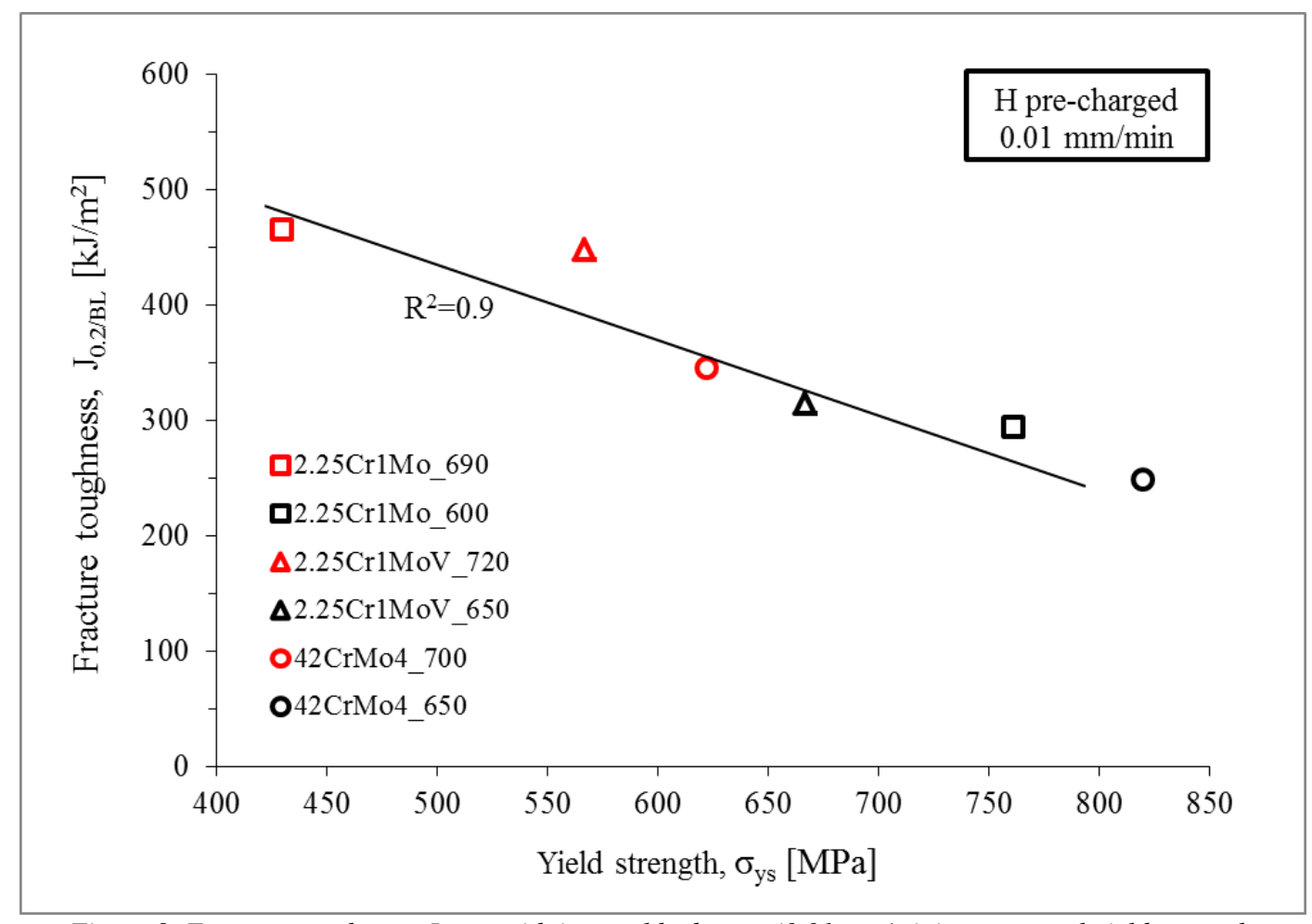

Figure 9. Fracture toughness, $J_{0.2 / B L}$, with internal hydrogen $(0.01 \mathrm{~mm} / \mathrm{min})$ versus steel yield strength.

\section{CONCLUSIONS}

The initial hydrogen content measured in $\mathrm{CrMo}$ and $\mathrm{CrMoV}$ steels pre-charged under high temperature hydrogen pressure increased with decreasing steel tempering temperature due to the fact that hydrogen microstructural trapping is greater in distorted, high energy martensitic microstructures. Moreover, the strongly trapped hydrogen content is even more dependent on the steel microstructure, increasing with decreasing tempering temperature and also as the result of the existence of vanadium carbides in $\mathrm{CrMoV}$ grades, which are recognized as being very strong hydrogen traps.

Fracture toughness measured with internal hydrogen strongly decreases with tempering temperature (higher yield strength as well as higher hydrogen retention), also being highly dependent on the applied displacement rate, as the accumulation of hydrogen atoms in the process zone located ahead of the crack tip of the CT fracture specimen increases due to the availability of longer diffusion times, thereby promoting the embrittlement phenomenon. This trend is consistent with the change appreciated in the fracture micromechanisms: MVC was the only failure micromechanism in uncharged specimens, changing to PRHIC and even IG (for the most embrittled grades) in tests performed with internal hydrogen, except in the $\mathrm{CrMoV}$ steel grade, in which the presence of hydrogen did not modify the failure micromechanism observed in tests performed in air.

High fracture toughness with internal hydrogen under low displacement rates (with high hydrogen accumulation within the process zone) were obtained in quenched and tempered $\mathrm{CrMo}$ and $\mathrm{CrMoV}$ steel grades even with yield strengths as high as $800 \mathrm{MPa}$. These grades could constitute good options for the manufacture of components to manage highpressure hydrogen gas.

\section{ACKNOWLEDGEMENTS}

The authors would like to thank the Spanish Ministry of Economy and Competitiveness for the support received to carry out research project MAT2014-58738-C3 (SAFEHIDROSTEEL) and to the Principado de Asturias government for the financing support given to the IDI/2018/000134 project. 


\section{REFERENCES}

[1] R. Von Helmolt, U. Ebele. Fuel cell vehicules: Status 2007. Journal of Power Sources 2007; 165: 833-843.

[2] R.P. Gangloff. Hydrogen assisted cracking in high strength alloys, in Comprehensive Structural Integrity. Elsevier Science 2013; 6.

[3] J. Yamabe, H. Matsunaga, Y. Furuya, S. Hamada, H. Itoga, M. Yoshikawa, E. Takeuchi, S. Matsuoka. Qualification of chromium-molybdenum steel based on the safety factor multiplier method in CHMC1-2014. Int J Hydrogen Energy 2015; 40: 717-728.

[4] J. Yamabe, T. Awane, S. Matsuoka. Investigation of hydrogen transport behaviour of various low-alloy steels with high-pressure hydrogen gas. Int J Hydrogen Energy 2015; 40(34): 11075-11086.

[5] L. Briottet, R. Batisse, G. de Dinechin, P. Langlois, and L. Thiers. Recommendations on X80 steel for the design of hydrogen gas transmission pipelines. Int J Hydrogen Energy 2012; 37(11): 9423-9430.

[6] J. H. Chuang, L.W. Tsay, c. Chen. Crack growth behaviour of heat-tretaed 4140 steel in air and gaseous hydrogen. Int. J. Fatigue 1998; 20(7): 531-536.

[7] M. Wang, E. Akiyama, and K. Tsuzaki. Effect of hydrogen on the fracture behavior of high strength steel during slow strain rate test. Corros Sci 2007; 49(11): 4081-4097.

[8] E. Akiyama, M. Wang, S. Li, Z. Zhang, Y. Kimura, N. Uno, K. Tsuzaki. Studies of evaluation of hydrogen embrittlement property of high-strength steels with consideration of the effect of atmospheric corrosión. Metallurgical and Materials Transactions 2013; 44A: 1290-1300.

[9] A. Zafra, L.B. Peral, J. Belzunce, C. Rodríguez. Effect of hydrogen on the tensile properties of $42 \mathrm{CrMo} 4$ steel quenched and tempered at different temperatures. Int. J. Hydrogen Energy 2018; 43: 9068-9082.

[10] R.P. Gangloff, B.P. Somerday. Gaseous hydrogen embrittlement of materials in energy technologies. Woodhead Publishingm, 2012.

[11] C. San Marchi, B.P. Somerday. Technical reference on hydrogen compatibility of materials, Sandia Report SAND2008-1163. Sandia National Laboratories, 2008.

[12] H. Barthelemy. Effects of pressure and purity on the hydrogen embrittlement of steels. Int J Hydrogen Energy 2011; 36: 2750-2758.

[13] Y. Ogawa, H. Matsunaga, J. Yamabe, M. Yoshikawa, S. Matsuoka. Unified evaluation of hydrogen-induced crack growth in fatigue tests and fracture toughness tests of a carbon steel. Int J of Fatigue 2017; 103: 223-233.

[14] S. Pillot, L. Coudreuse. Hydrogen-induced disbonding and embrittlement of steels used inpetrochemical refinining. Woodhead Publishing Limited, 2012.

[15] J. H. Liu, L. Wang, Y. Liu, X. Song, J. Luo, D. Yuan. Effects of hydrogen on fracture toughness and fracture behaviour of SA508-III steel. Mater. Res. Innovations 2014; 18(4): 255-259.

[16] C. Colombo, G. Fumagalli, F. Bolzoni, G. Gobbi, L. Vergani. Fatigue behaviour of hydrogen pre-charged low alloy Cr-Mo steel. Int J of Fatigue 2016; 83: 2-9.

[17] A. W. Loginow, E.E. Phelps. Steels for seamless hydrogen pressure vessels. Corrosion 1975; 31: 404-412.

[18] Y. Li, B. Gong, A. Li, C. Deng, D. Wang. Specimen thickness effect on the property of hydrogen embrittlement in single edge notch tension testing if high strength pipeline steel. Int $\mathbf{J}$ Hydrogen Energy 2018; 43: 1557515585.

[19] R. L.S. Thomas, J.R.Scully, R. Gangloff. Internal hydrogen embrittlement of ultrahigh-strength AERMET 100 steel. Metallurgical and Materials Transactions A 2003; 34: 327-344.

[20] I.M. Robertson, P. Sofronis, A. Nagao, N.L. Martin, S. Wang, D.W. Gros, K.E. Nygren. Hydrogen embrittlement understood. Metallurgical and Materials Transactions 2015; 46B: 1085-1103. 
[21] T. Mitchler, C. San Marchi, J. Naumann S. Weber, M. Martin. Hydrogen environment embrittlement of stable austenitic steels. Int J Hydrogen Energy 2012; 37: 16231-16246.

[22] ASTM E1820. Standard test method for measurement of fracture toughness. Annual Book of ASTM Standards 2015; 03.01 .

[23] George Krauss. Steels: Processing, Structure and Performance. ASM International, 2005.

[24] J. Lee, T. Lee, Y.J. Kwon, D.J. Mun, J.Y. Yoo, C. S. Lee. Effects of vanadium carbides on hydrogen embrittlement of tempered martensitic steel. Met. Mater. Int 2016; 22( 3): 364-372.

[25] X.Y. Cheng, H. Li, X.B. Cheng. Carbides and possible hydrogen irreversible trapping sites in ultrahigh strength round steel. Micron 2017; 103: 22-28.

[26] R.M. McMeecking, D.M. Parks. On criterioa for J-dominance of crack-tip filds in large-scale yielding. ASTM STP 668, American Society for Testing and Materials, Philadelphia, 1979, 175-194.

[27] P. Sofronis, R.M. McMeecking. Numerical analysis of hydrogen transport near a blunting crack tip, $J$. Mechanic Phys. Solids 1989; 37: 317-350.

[28] K. A. Nibur, B. P. Somerday, C. S. A. N. Marchi, J. W. Foulk, M. Dadfarnia, and P. Sofronis. The Relationship Between Crack-Tip Strain and Subcritical Cracking Thresholds for Steels in High-Pressure Hydrogen Gas. Metall. Mater. Trans. A 2013; 44A: 248-269.

[29] Y. Takeda and C. J. McMahon Jr. Strain controlled vs. stress controlled hydrogen induced fracture in a quenched and tempered steel. Metall. Mater. Trans. A 1981;12A: 1255-1266.

[30] A. Nagao, M.L. Martin, M. Dadfarnia, P. Sofronis, I.M. Robertson. The efect of nanonsized (Ti,Mo)C precipitates on hydrogen embrittlement of tempered lath martensitic steels. Acta Materialia 2014; $244-254$.

[31] Y. Murakami and S. Matsuoka. Effect of hydrogen on fatigue crack growth of metals. Eng. Fract. Mech 2010; 77(11): 1926-1940.

[32] N. Parvathvarthini, S. Saroja, R.K. Dayal, H.S. Khatak. Studies on hydrogen permeability of $2.12 \% \mathrm{Cr}-1 \% \mathrm{Mo}$ ferritic steel: correlation with microstructure. Journal of Nuclear Materials 2001; 288: 187-196. 